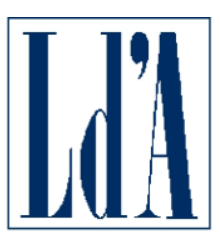

CENTRO STUDI LUCA D'AGLIANO

WWW.DAGLIANO.UNIMI.IT

CENTRO STUDI LUCA D'AGLIANO

DEVELOPMENT STUDIES WORKING PAPERS

N. 360

December 2013

Trade across Countries and Manufacturing Sectors with Heterogeneous Trade Elasticities

Stefano Bolatto*

* University of Turin and CERIS-CNR 


\title{
Trade across Countries and Manufacturing Sectors with Heterogeneous Trade Elasticities*
}

\author{
Stefano Bolatto \\ University of Turin and CERIS-CNR
}

\begin{abstract}
Multi-sector versions of the international trade model of Eaton and Kortum (2002) usually restrict trade elasticities to be identical across sectors, with potentially distorting effects on the estimates of the model parameters. This paper allows for heterogeneous sectoral trade elasticities and quantifies them by estimating an equation for bilateral market shares, with tariffs and standard gravity variables used to model trade barriers. Results show that sectors differ significantly in the size of trade elasticities. The paper proves that this heterogeneity matters at least in three different respects. First, it matters when inferring measures of relative productivity from trade and production data. Secondly, it matters when considering the trade-induced reallocations of production within and between sectors. When assessing their relative contribution to the productivity gains that each country obtains from opening to trade, gains turn out to be largely due to the reallocation within sectors, especially for richer countries. Finally, accounting for the heterogeneity in elasticities is crucial when running general equilibrium counterfactual studies, such as that performed in this paper, which assesses the effects on aggregate of sector-specific technology shocks.
\end{abstract}

JEL classification: F10, D24, C50, L60, O40

Keywords: Eaton-Kortum model; technological heterogeneity; gravity equations; trade elasticities; export costs; productivity gains from trade; reallocation between and within sectors.

* I would like to thank my advisor Massimo Sbracia for his invaluable encouragement and guidance. I owe a huge debt of gratitude to Jonathan Eaton for all his suggestions and support. I wish to thank Giorgio Barba Navaretti, Federico Boffa and Fabio Montobbio for many useful comments on earlier drafts. This paper has been mainly written during my visit at the Department of Economics of the Pennsylvania State University (PSU), whose fruitful hospitality is gratefully acknowledged. Special thanks go to Mark Roberts, James Tybout and Stephen Yeaple for helpful discussions about my research and to Konstantin Kucheryavyy for providing me with precious advice for the codes used in the estimation procedure. I also benefited from comments from Jacopo Bizzotto, Toomas Hinnosaar, David Jinkins, Ahmad Lashkaripour, Kai Li, Gary Lyn, Corrado Macchiarelli, Mario Pagliero, Christian Soegaard, Felix Tintelnot and from seminar participants at PSU, ETSG 2013, Collegio Carlo Alberto, KU Leuven and the MOOD 2013 Workshop hosted at the EIEF in Rome. All the remaining errors are mine. E-mail: stefanoantonio.bolatto@unito.it 


\section{Introduction}

Quantitative studies of bilateral trade flows received a massive boost from the development of new models of international trade, and especially from the perfect competition model of Eaton and Kortum (2002; EK hereinafter) and the monopolistic competition model with entry-costs in the export market proposed by Melitz (2003). While the latter provides a theoretical reference for firm-level studies, the former has been largely used for empirical studies on bilateral trade data and for general equilibrium counterfactual exercises.

Given the large availability of trade data disaggregated by product category, these exercises become particularly interesting when performed for an open economy with multiple sectors. In this way, one can assess the welfare effects of trade liberalizations or productivity shocks (possibly sector-specific) caused by the forward and backward linkages among sectors. Over the last few years, the EK model has therefore been generalized by developing multisector extensions (see Shikher, 2011 and 2012; Eaton et al. 2011; Levchenko and Zhang, 2011; and Costinot, Donaldson and Komunjer, 2012).

These models use probability distributions to describe the technological heterogeneity of individual producers within each sector. A common feature of these models is that, typically for technical convenience, they impose assumptions on the parameters of the distributions. This restricts trade elasticities to be common across the manufacturing sectors that span the whole space of tradable goods. Since different sectors correspond to very different product categories, this implication is clearly unsatisfactory: a given percentage change in one of the variables affecting trade costs is likely to induce different variations in the amount of imports of, say, food and textile products.

This paper shows that trade elasticities vary significantly across sectors and claims that exploiting this cross-sector heterogeneity can lead us to assess more precisely the determinants of trade patterns and the welfare effects of trade openness. For this purpose, the paper develops a variant of EK with multiple sectors, in which trade elasticities are allowed to vary by sector. The theoretical framework features both labor and intermediate-goods inputs. The economy consists of a finite number of sectors, each of them modeled as a distinct continuum of individual producers. In each sector, the level of efficiency of each manufacturer is represented by a draw from a country-and-sector specific distribution. Each distribution is then assumed to be a Fréchet, characterized by two parameters: a scale parameter, reflecting the state-ofthe-art technology and assumed to be country-and-sector specific, and a shape parameter, common to all countries, which measures the within-sector dispersion in efficiency among producers.

In any model featuring micro-fundations à la EK, this sectoral measure of dispersion is also the size of the import elasticity with respect to variable trade costs in that sector. In contrast with most of the related literature, in which the shape parameter is restricted to be invariant across sectors, this paper allows for sectoral distributions of efficiencies to have different shape. The trade model is used to derive a reduced form, in which tariff rates are used to directly infer, sector-by-sector, the values of the shape parameter as well as the trade elasticities with respect to any variable used in modeling trade costs. GLS estimates for 13 different manufacturing sectors, obtained using a sample of 51 developed and developing countries, show that import elasticity to trade costs ranges from slightly less than 2 to almost 
11. Interestingly, this is very similar to the range of estimates that has been identified in literature for the aggregate value of trade elasticity when considering the manufacturing sector as a whole. ${ }^{1}$

The paper shows that this cross-sector heterogeneity matters, at least in three different respects. First, by accounting for this heterogeneity one can correctly infer measures of countries' relative productivity from "easy-to-get" data on trade and production. ${ }^{2}$ Especially in some sectors, the assumption of common shape parameters is proved to induce a large bias in the estimate of the scale parameter of the efficiency distribution. This, in turn, leads to a biased estimate of the countries' average efficiencies across sectors and therefore to an improper reconstruction of the cross-countries pattern of comparative advantages.

Secondly, the heterogeneity in trade elasticities matters when measuring countries' gains from trade and, in particular, when assessing the relative contribution of the different kinds of resource reallocations -within and between sectors- induced by trade openness. The measurement of the benefits due to reallocations within-sectors, in particular, crucially depends on a proper estimation of the sectoral labor productivity indices. The latter can be biased by the assumption of common trade elasticity across sectors. Furthermore, the role of sectoral heterogeneity in determining the size of the gains for each country appears as a promising topic for future research, as confirmed by a very recent paper of Levchenko and Zhang (2013), based on a Ricardian-Heckscher-Ohlin model.

Finally, the paper shows that an accurate estimate of sectoral trade elasticities is key also to run general equilibrium counterfactual studies. Starting from the estimated sectoral elasticities, the paper performs a counterfactual simulation, in which the effects of a productivity shock in a single sector spread to the rest of the economy through the intermediategoods channel. Results suggest that aggregate productivity rises the most when productivity shocks occur in sectors that (i) represent a large share of spending and (ii) are characterized by a higher trade elasticity. By imposing common trade elasticity, results are biased in favor of the manufacturing sector with the largest share in total expenditure.

This paper is strictly related to Caliendo and Parro (2012), who also develop a variant of EK with sector-specific dispersion of efficiencies, but differs along two main directions. The first is the econometric approach. The procedure outlined in this paper repeats on a sectorby-sector basis the "gravity-type" methodology adopted by EK, with the simple addition of tariff rates into the iceberg cost specification. ${ }^{3}$ This methodology delivers not only estimates of the sectoral shape parameters, but also estimates of the various sectoral elasticities of trade, such as the transport cost elasticity to distance. This provides useful information in order to carefully reconstruct trade barriers incurred by countries across both destinations

\footnotetext{
${ }^{1}$ Results from Imbs and Mejean (2009) and Chen and Novy (2012) suggest that different degrees of dispersion in efficiency across sectors are likely to be related to the heterogeneities in the within-sector elasticities of substitution.

${ }^{2}$ It is worth noting that, while trade elasticities are estimated from an extended sample of 51 countries, the analysis of countries' relative productivity across sectors is performed for a subset of 20 countries, for which richer data is available.

${ }^{3} \mathrm{~A}$ direct comparison between the estimated trade elasticities of the two papers is not possible, since the latter makes use of different data and sectoral classifications. Nevertheless, it is worth mentioning that the GLS estimates reported here bear some resemblance of the values reported in Caliendo and Parro's paper. Due to some restrictions on parameters, commonly adopted in this body of literature, the former are generally more consistent, however, with the assumption of substitutability among similar products than the latter.
} 
and sectors. The second difference with respect to Caliendo and Parro is that this paper also investigates the implications of the cross-sector heterogeneity in trade elasticities, in particular when estimating the other model parameters.

This paper is also related to Costinot, Donaldson and Komunjer (2012) and Shikher (2011), even though they assume common shape parameters. As in both of these papers, countries' average efficiencies are here inferred form sectoral data on production and trade flows. ${ }^{4}$ This paper accomplishes this task by adopting an original methodology, which no longer imposes additional structure into the empirical model and does not impose long-run equilibrium conditions, fitting a subset of the model (i.e. a simplified output equation) to the data. $^{5}$

Finally, this paper is also related to Arkolakis, Costinot and Rodríguez-Clare (2012). They show that, for a large class of "quantitative" models that includes EK, welfare gains from trade can be quantified using only two sufficient statistics: $(i)$ the share of spending in tradeable goods represented by home-made products and (ii) the aggregate trade elasticity, i.e. the shape parameter of the efficiency distribution across all manufacturing industries. In order to investigate their composition, gains are computed here in terms or labor productivity, rather than welfare. This paper shows that gains in terms of labor productivity can be consistent with those computed in terms of welfare, given a suitable choice of the key parameters of the model. Furthermore, the analysis assesses the relative importance of input reallocations, between and within sectors, in determining the overall productivity gains computed for each economy. For a restricted sample of 20 countries, this exercise shows that productivity gains from trade are mostly due to reallocations that occur within each sector, which determines from 75 to $90 \%$ of the whole gains. The contribution of the reallocation between sectors, which is the complement to 100, is much lower, and especially so in the most industrialized economies. In this respect, the findings of this paper are consistent with those of Pavcnik (2002), among others, but are derived form (sector-level) aggregate data, rather than firm-level data. This shows the possibility to investigate the big issue of the trade-induced reallocations by running meaningful cross-countries comparisons, given the large availability of data, at that level of aggregation, for many different countries.

\footnotetext{
${ }^{4}$ In the literature following EK, productivity measures are "trade-revealed": instead of being the residuals of production functions, they are those consistent with data on production, import and export. The standard methodology entails choosing a functional form for the aggregate production function, measuring output and inputs and then obtaining TFP as a residual. One critical step of this methodology is the availability of reliable data on physical capital. The perpetual inventory approach usually adopted for this purpose has many drawbacks: it requires long time series on fixed investments and price deflators, a guess for the initial level of capital stock, and heroic assumptions about the depreciation rate of capital. The alternative approach, based on production and trade data, has the key advantage that it is the cost of the inputs, and not their quantities, that matters to retrieve productivity, thereby attenuating some of the problems of the standard methodology. Finicelli, Pagano and Sbracia (2013) show that the "trade-revealed" measure of average productivity among domestic industries approximates the TFP of the economy's aggregate production function.

${ }^{5}$ For each manufacturing sector, Costinot, Donaldson and Komunjer estimate the countries' relative mean efficiencies by combining market-shares attained by two different countries in a third one and regressing the resulting equation using alternative procedures. This methodology has been later used by Caliendo and Parro (2012). On the other hand, the procedure suggested by Shikher (2011) entails estimating bilateral tradeequations, sector by sector, on a set of regressors that includes standard gravity variables and then fitting a subset of the model to data. One limitation of this procedure is represented by the necessarily imposition of long-run equilibrium conditions, as well as the use of a simplified version of the (cumbersome) output equation of the model.
} 
The rest of the paper is organized as follows. Section 2 outlines the model. Section 3 estimates trade elasticities by combining structural equations for bilateral trade with a proper specification of trade costs. Section 4 derives relative price indices and average efficiencies. Section 5 provides a decomposition of the labor productivity gains from trade, to assess the relative importance of within- and between-sector reallocations. Section 6 presents a counterfactual study, in which sectoral productivities are exogenously increased in order to find those that have the largest impact at the aggregate level, and draws some policy recommendations. Section 7 concludes.

\section{Theoretical framework}

\subsection{The basic environment}

Consider a world with $N$ different countries. In each country, the space of tradable goods comprises $K$ manufacturing sectors. Each sector, in turn, features a continuum of differentiated commodities. All countries are potential producers of any of these goods, using the best technology available at their location. ${ }^{6}$ In the original spirit of EK, country $i$ 's efficiency in producing good $j$ in sector $k$, denoted as $z_{i, k}(j)$, is assumed to be the realization of a random variable $Z_{i, k}$ drawn from a Fréchet distribution with parameters $T_{i, k}$ and $\theta_{k}$. Any country is then characterized by $K$ different distributions with c.d.f.: $F_{i, k}(z)=\exp \left\{-T_{i, k} z^{-\theta_{k}}\right\}$. These distributions are assumed to be independent across both countries and sectors.

The scale parameter $T_{i, k}$ sets the state of technology: a higher value implies that, in sector $k$ of country $i$, a high efficiency draw is more likely for any $j$. The shape parameter $\theta_{k}$ regulates the degree of technological heterogeneity among industries within sector $k{ }^{7}$ Importantly, this parameter is allowed to vary by sector.

Labor is the sole primary input and is mobile across sectors and fixed at country level. ${ }^{8}$ Within each country, wage adjusts to ensure full employment. The input bundle also includes intermediate goods, which are not distinguishable from final goods: each commodity can be used indifferently by firms and consumers.

Production technology is Cobb-Douglas for any industry, sector and country:

$$
Q_{i, k}(j)=z_{i, k}(j) L_{i, k}^{\beta_{k}}(j) \prod_{h=1}^{K}\left[M_{i, k h}(j)\right]^{\left(1-\beta_{k}\right) \eta_{h k}},
$$

\footnotetext{
${ }^{6}$ Recall that industry and sector have a different meaning: (i) the term industry describes one or many identical firms producing the same good $j$ at a given location; (ii) the term sector refers to a group of industries producing differentiated goods, which can be assimilated into the same product category. In this paper, the whole manufacturing sector is broken down into a finite number of (sub)sectors and each of them, in turn, includes a continuum of industries.

${ }^{7}$ The shape parameter of the efficiency distributions quantifies the pressure that comparative advantage exerts in favor of international trading, whereas the scale parameter is typically interpreted as a measure of country $i$ 's absolute advantage. Provided that $Z_{i, k} \sim \operatorname{Fréchet}\left(T_{i, k}, \theta_{k}\right)$ and $Z_{n, k} \sim \operatorname{Fréchet}\left(T_{n, k}, \theta_{k}\right)$, if $T_{i, k}>T_{n, k}$ then $Z_{i, k}$ first-order stochastically dominates $Z_{n, k}$.

${ }^{8}$ Since this paper develops a static model of trade, any inter-temporal choice or dynamics are extraneous to the analysis. Therefore, for clarity of exposition and notational convenience, capital is not included among the inputs. An alternative approach could be that of measuring labor inputs in terms of capital-equipped labor units, provided that every country is endowed with a fixed stock of capital. In that case, wage data should be adjusted for a measure of the return for capital at any location.
} 
where $\beta_{k}$ is the sectoral share of value-added in total output, $L_{i, k}(j)$ is the labor input used by industry $j$ and $M_{i, k h}(j)$ is the amount of goods produced in sector $h$ and used as intermediate for producing good $j$ in sector $k$. Constant-return-to-scale necessarily implies $\sum_{h=1}^{K} \eta_{k h}=1$, where $\eta_{k h}$ is the weight on inputs from the source-sector $h$ in producing goods in sector $k$.

Under these assumptions, the unit cost of an input bundle turns out to be:

$$
c_{i, k}=w_{i}^{\beta_{k}} \rho_{i, k}^{1-\beta_{k}} \quad \text { where } \rho_{i, k}=\prod_{h=1}^{K} p_{i, h}^{\eta_{h k}},
$$

where $w_{i}$ is the nominal wage in country $i$ and $\rho_{i, k}$ is the price index of intermediate inputs employed in sector $k$. A simplifying assumption (commonly used in the literature built on EK) is that -within each sector- goods are demanded in the same proportion by consumers and firms. It follows that $\rho_{i, k}$ can be computed starting from the $K$ sectoral consumer-price indices in country $i$, defined as:

$$
p_{i, k}=\left[\int\left(p_{i, k}(j)\right)^{1-\sigma_{k}} d G_{i, k}(p)\right]^{\frac{1}{1-\sigma_{k}}},
$$

where $\sigma_{k}$ is the within-sector elasticity of substitution among goods, which can differ by sector, and $G_{i, k}(p)$ denotes the price distribution of goods in sector $k$ and country $i$, unconditional on their source. As shown in Appendix B, the latter is a Weibull distribution with shape parameter $\theta_{k}$ and scale parameter given by:

$$
\Phi_{i, k} \equiv \sum_{n=1}^{N} T_{n, k}\left(c_{n, k} d_{i n, k}\right)^{-\theta_{k}},
$$

which is the price parameter commonly defined as a measure of "multilateral resistance" to trade. Exploiting the properties of Weibull distributions, one can derive the exact price-index in sector $k$ and country $n$ :

$$
p_{i, k}=\gamma_{k} \Phi_{i, k}^{-1 / \theta_{k}} \quad \text { where } \gamma_{k} \equiv\left[\Gamma\left(\frac{\theta_{k}+1-\sigma_{k}}{\theta_{k}}\right)\right]^{\frac{1}{1-\sigma_{k}}} .
$$

In this setting, every country is a potential supplier of any $j$ to any destination $i$, where its products can be shipped at the following price:

$$
p_{n i, k}(j)=\frac{c_{i, k} d_{n i, k}}{z_{i, k}(j)}
$$

where $d_{n i, k} \geqslant 1$ is the iceberg cost (consisting of transport costs, tariffs and other trade barriers) incurred by source $i$ when shipping one unit of goods to destination country $n$. These costs are allowed to differ by destination, by source and even by sector. ${ }^{9}$ As usual,

\footnotetext{
${ }^{9}$ International trade is subject to additional costs due to transportation, tariffs and any other natural or artificial barrier. In general equilibrium modeling of international trade, the fact of treating trade costs as additive usually leads to severe impediments in computation. Hence, they are generally assumed to act multiplicatively, as in Samuelson (1952): for one unit of good to arrive at country $i$ from $n, d_{n i}>1$ units of the good must be shipped. This specification is indeed supported by some theoretical foundations, especially when trade costs explicitly include tariffs, the latter being usually set as ad-valorem duty rates. Nevertheless, the empirical evidence on the nature of trade costs is not conclusive. Hummels and Skiba (2004) regress freight costs on FOB prices for many destinations and for a wide range of narrowly defined product categories. Even if freight costs turn out to rise with FOB prices, the corresponding elasticity is estimated to be lower than one (the value predicted by a multiplicative specification), even though vastly larger then zero (the value implied by the purely additive specification). Further investigation into this issue is highly desirable, given that freight costs are just one of the several components of trade barriers.
} 
$d_{i i, k}$ is normalized to one: additional costs only occur when commodities are shipped abroad. A simple triangle inequality rules out any arbitrage condition in international trade: $d_{n i, k} \leq$ $d_{n m, k} d_{m i, k}$ for any $i, n, m=1, \ldots, N$.

In perfect competition, each market is served only by the cheapest source. Consequently, the price actually paid by consumers in country $n$ when purchasing good $j$ in sector $k$ is: $p_{n, k}(j)=\min \left\{p_{n i, k}(j)\right\}_{i=1}^{N}$, which is the only price entering into the CES aggregator given by (2).

Finally, to shape the demand-side of the economy, the representative agent is required to solve a standard utility-maximization; the objective function mixes in a Cobb-Douglas fashion the amounts of goods consumed originating from the $K$ different sectors. These quantities, in turn, result from a CES aggregation of the amounts of individual goods $j$ consumed in each sector. The consumer's problem is then:

$$
\max _{C_{i, k}(j)} U_{i}=\prod_{h=1}^{K}\left[\int_{j \in k} C_{i, k}(j)^{\frac{\sigma_{k}-1}{\sigma_{k}}} d j\right]^{\frac{\sigma_{k}}{\sigma_{k}-1} \alpha_{k}} \operatorname{sub} \sum_{k=1}^{K} p_{i, k} C_{i, k} \leq w_{i} L_{i} \equiv Y_{i},
$$

where $Y_{i}$ is country $i$ 's value-added in manufactures, $C_{i, k}(j)$ denotes the consumption of good $j$, and $C_{i, k}$ is the overall consumption of commodities in sector $k$. The taste parameter $\alpha_{k} \in[0,1]$ measures the share represented by spending on commodities from sector $k$ upon the total spending in manufacturing goods; this share is the same everywhere because of homothetic preferences.

\subsection{Market-shares equations}

The overview of the model has to be completed by analyzing its predictions in terms of trade patterns. In particular, the EK model has the following useful property: any source $i$ exploits its comparative advantage in a given market $n$ by selling a wider range of commodities, up to the point at which the distribution of the prices of the goods exported to market $n$ is equal to $n$ 's overall price distribution. ${ }^{10}$ This result has an important implication: in any open economy, the price index at sector level only depends on the price distribution of the goods actually produced by domestic industries.

Because average spending per good does not vary by source, the fraction of goods that country $i$ purchases from source $n$ in each sector is also the fraction of country $i$ 's spending on goods imported from $n$. By the law of large numbers, the probability that country $i$ is the cheapest source in sector $k$ in country $n$, namely $\pi_{n i, k}$, coincides with country $i$ 's share in country $n$ 's spending in sector $k$ :

$$
\pi_{n i, k}=\frac{X_{n i, k}}{X_{n, k}}=\frac{T_{i, k}\left(c_{i, k} d_{n i, k}\right)^{-\theta_{k}}}{\Phi_{n, k}} .
$$

In the above equation, $X_{n i, k}$ is the total spending in sector $k$ and country $n$ conditional on goods being supplied by country $i$, while $X_{n, k}$ is the overall spending in country $n$ and

\footnotetext{
${ }^{10}$ To illustrate this result, consider equations (3) and (4). The price parameter $\Phi_{i k}$ does not depend on how much country $i$ buys from any of its trade partners, but only on the state variables of the various economies (i.e. their states of technology, the unit costs of their inputs and the iceberg costs incurred when shipping to destination $i$ ).
} 
sector $k$. Notice that country $i$ 's share in market $n$ can also be interpreted as country $i$ 's contribution to the "multilateral resistance" parameter of destination $n$.

Economic intuitions behind equation (6) are widely discussed in EK. Those considerations are still valid when referred to a specific sector, rather than the manufactures as a whole. ${ }^{11}$ Appendix C proves that equation (6) holds even in case of Bertrand, rather than perfect competition.

\section{Estimation of the shape parameters}

\subsection{The econometric model}

The empirical implementation of the model entails estimating the two parameters of the efficiency distribution, across both countries and sectors. The first step is represented by the estimation of the sector-specific values of the shape parameter, namely $\theta_{k}$. The procedure sketched in this section is built on that originally used by EK for their model with a unique, undifferentiated continuum of tradeable goods.

Equations (1), (3) and (4) can be combined in order to re-write (6) as follows:

$$
\frac{X_{n i, k}}{X_{n, k}}=T_{i, k}\left(\gamma_{k} \frac{w_{i}^{\beta_{k}} \rho_{i, k}^{1-\beta_{k}} d_{n i, k}}{p_{n, k}}\right)^{-\theta_{k}} .
$$

Standard steps, reported in Appendix D, lead to the following equation:

$$
\frac{X_{n i, k}}{X_{n n, k}}=\frac{X_{i i, k} / X_{i, k}}{X_{n n, k} / X_{n, k}} \frac{T_{i, k}}{T_{n, k}}\left(\frac{w_{i}}{w_{n}}\right)^{-\beta_{k} \theta_{k}}\left(\frac{\rho_{i, k}}{\rho_{n, k}}\right)^{-\left(1-\beta_{k}\right) \theta_{k}} d_{n i, k}^{-\theta_{k}},
$$

which can be reduced as follows, by taking logs:

$$
\ln X_{n i, k}^{\prime}-\ln X_{n n, k}^{\prime}=-\theta_{k} \ln d_{n i, k}+S_{i, k}-S_{n, k},
$$

where $\ln X_{n i, k}^{\prime} \equiv \ln X_{n i, k}-\ln \left(X_{i i, k} / X_{i, k}\right)$ and $\ln X_{i i, k}^{\prime} \equiv \ln X_{n n, k}-\ln \left(X_{n n, k} / X_{n, k}\right)$. Equation (9) is the sector-level counterpart of equation (28) in EK. As in that formulation, all country $i$-specific determinants of trade are captured as a source-fixed effect, by setting:

$$
S_{i, k} \equiv \ln T_{i, k}-\beta_{k} \theta_{k} \ln w_{i}-\left(1-\beta_{k}\right) \theta_{k} \ln \rho_{i, k},
$$

which can be interpreted as a measure of country $i$ 's competitiveness in sector $k$.

\subsection{Trade-costs specification with tariffs}

Throughout this paper, iceberg costs are specified according to the asymmetric cost model proposed by Caliendo and Parro (2012, CP in the aftermath): they are the sum of a (nonsymmetric) tariff and a non-tariff component, which is generally assumed to be non-symmetric

\footnotetext{
${ }^{11}$ Notice that country $i$ 's exports to market $n$ are decreasing in $\Phi_{n, k}$ : advanced technologies and/or low input-costs in third countries can provide country $n$ with good alternative opportunities for buying, thus penalizing country $i$ 's exports. Moreover, high values for $\Phi_{n, k}$ can arise form low iceberg costs incurred by foreign countries when shipping to country $n$.
} 
as well. A very simple formulation arises when tariffs are ad valorem c.i.f.. By taking this convention, the tariff component applies multiplicatively to the value of merchandise, as calculated at the time of delivery at the importers' frontier. This value already embeds insurance and freight charges incurred up to that moment. Assuming all these charges to be proportional to the FOB price (see footnote 12), the log of iceberg costs turn out to be:

$$
\ln d_{i n, k}=\ln \tau_{i n, k}+\ln \delta_{i n, k},
$$

where $\tau_{i n, k}=\left(1+\widetilde{\tau}_{i n, k}\right)$ and $\widetilde{\tau}_{i n, k}$ is the ad-valorem duty rate paid by $i$ to deliver to $n$. Non-tariff barriers, namely $\delta_{i n, k}$, consist of transport costs and any other charge related to proximity, language or treaties. ${ }^{12}$

While distance between locations is usually segmented into intervals and then captured by means of dummy variables, this paper treats distance as a continuous variable, as in Santos Silva and Tenreyro (2006). In particular, $\delta_{i n, k}$ are modeled as increasing functions in the number of kilometers between $i$ and $n$, raised to the power of some positive $\rho_{k}<1$, which implies a decreasing marginal cost of transportation. ${ }^{13}$ Transport costs are sector-specific and include a blow-up factor, which is a convenient (exponential) function of a set of conventional dummy variables:

$$
\begin{aligned}
\delta_{n i, k} & =\left(\text { dist }_{n i}\right)^{\rho_{k}} \exp \left\{\phi_{n i, k}+\varepsilon_{n i, k}\right\} \\
\text { where } \phi_{n i, k} & \equiv \xi_{1, k} b_{n i}+\xi_{2, k} l_{n i}+\xi_{3, k} t_{n i}+\xi_{4, k} h_{n i} .
\end{aligned}
$$

In the above expression, $b_{n i}$ is the indicator variable for shared borders, $l_{n i}$ for common language, $t_{n i}$ for past colonial ties and finally $h_{n i}$ for common legal origin between country $i$ and $n$. For convenience of notation, the linear combination of these four variables is summarized by $\phi_{n i, k}$.

With respect to the iceberg cost specification, one might argue about the absence of an importer fixed effect, whose inclusion is a common practice in gravity models. In particular, this fixed effect is necessary in all empirical studies which neglect tariff data, in order to avoid symmetry in trade costs. Waugh (2010) provides a clear treatment of this point, showing that an importer-fixed effect generates the same pattern of trade costs as an exporter-fixed effect. Although the two specifications are interchangeable and fit bilateral trade data equally well, normally researchers specify the fixed effect as an overall destination-effect. Consequently, as stressed by Shikher (2005), its economic interpretation boils down to a measure of the importer's degree of trade openness. ${ }^{14}$ For this reason, it is not surprising that tariffs turn out to be not statistically significant when an importer fixed-effect is included into the iceberg cost

\footnotetext{
${ }^{12} \mathrm{~A}$ good produced by country $i$ in sector $k$ can be sold in market $n$ at price $p_{i n, k}=\tau_{i n, k} \delta_{i n, k} p_{i i, k}$, where $p_{i i, k}$ is the FOB price and $\tau_{i n, k}$ is the tariff rate applied by the importer on the CIF value of the good, as measured at the time of delivery. In this specification non-tariff barriers $\delta_{i n, k}$ therefore include all charges that generate a spread between the FOB and CIF prices by acting multiplicatively with respect to the FOB value.

${ }^{13}$ This specification is equivalent to including the log of distance in the argument of an exponential function. In that case, $\ln \left(\right.$ dist $\left._{n i}\right)$ would enter in an additive form with respect to the dummy variables collected into $\phi_{n i, k}$ and would be associated to the coefficient $\xi_{0, k}=\rho_{k}$. Given the properties of the logarithmic functions, even in that formulation transport would be characterized by decreasing marginal costs with respect to distance even in that formulation.

${ }^{14}$ In Shikher's (2005) formulation, the exporter fixed effect corresponds to $D_{i, k}^{\exp }=S_{i, k}$ while the importer fixed effect is: $D_{n, k}^{i m p}=-\theta_{k} m_{n, k}-S_{n, k}$, where $m_{n, k}$ is the importer fixed effect. Consequently, destination-
} 
formulation, as a result of severe problems of multicollinearity. One might argue that a fixed effect for destination should be included anyway, in order to capture other country-specific conditions, such as good infrastructures, facilities or direct access to the sea. Nevertheless, these conditions should be assessed for either the destination and source country and should affect bilateral trade in both directions. Based on these considerations, the importer fixed effect has been left out in this paper.

Finally, since economic relations are expected to hold on average, deviations have to be introduced into the model. In this paper, they enter in form of measurement errors: the disturbance $\varepsilon_{n i, k}$ is included in the specification of non-tariff barriers $\delta_{n i, k}$, the latter being not directly observable, but "reconstructed" on the basis of an arbitrary function.

Therefore, the structural equation for trade is:

$$
\ln \frac{X_{n i, k}^{\prime}}{X_{n n, k}^{\prime}}=-\theta_{k} \ln \tau_{n i, k}-\theta_{k} \rho_{k} \ln d i s t_{n i}-\theta_{k} \phi_{n i, k}+S_{i, k}-S_{n, k}-\theta_{k} \varepsilon_{n i, k},
$$

which constitutes the basis of the estimation. The error term is assumed to be orthogonal to tariffs and any other regressor. At a first glance, this model might appear suitable for a standard OLS estimation, like those run in many standard gravity studies. Due to the assumption of mutual independence among sectoral efficiency distributions, equations (11) can be regressed, independently, sector by sector.

\subsection{Efficiency and refinements}

OLS estimates of equation (11) could return biased results. In particular, in standard gravity equations à la Anderson and Van Wincoop (2003), Santos Silva and Tenreyro (2006) find robust evidence that error terms are not statistically independent from the regressors. Tests performed using OLS estimates clearly reveal the presence of heteroskedasticity even in the bilateral trade equations implied by the multi-sector extension of EK outlined in this paper. To address the issue, it is useful to implement a procedure originally developed by EK. Let the disturbance term $\varepsilon_{n i, k}$ be made up of two components:

$$
\varepsilon_{n i, k}=\varepsilon_{n i, k}^{I}+\varepsilon_{n i, k}^{I I} .
$$

Within each sector, error terms have a symmetric, country-pair specific component, namely $\varepsilon_{n i, k}^{I}$ (with $\varepsilon_{n i, k}^{I}=\varepsilon_{i n, k}^{I}$ ), and an additional component, namely $\varepsilon_{n i, k}^{I I}$, which affects trade only in one way. Their corresponding variances are denoted with $\sigma_{I, k}^{2}$ and $\sigma_{I I, k}^{2}$, respectively. The variance-covariance matrix implied by this particular error structure is a non-diagonal matrix: the elements on the main diagonal are given by $E\left(\varepsilon_{n i, k} \varepsilon_{n i, k}\right)=\sigma_{I, k}^{2}+\sigma_{I I, k}^{2}$, while the remaining off-diagonal elements are alternatively zeros or $E\left(\varepsilon_{n i, k} \varepsilon_{i n, k}\right)=\sigma_{I I, k}^{2}$.

The regression model actually used in this exercise is thus:

$$
\begin{aligned}
\ln \frac{X_{n i, k}^{\prime}}{X_{n n, k}^{\prime}}= & -\theta_{k} \ln \tau_{i n, k}-\theta_{k} \rho_{k} \ln \left(\text { dist }_{n i}\right)-\theta_{k} \xi_{1, k} b_{n i}-\theta_{k} \xi_{2, k} l_{n i}+ \\
& -\theta_{k} \xi_{3, k} c_{n i}-\theta_{k} \xi_{4, k} h_{n i}+S_{i, k}-S_{n, k}-\theta_{k}\left(\varepsilon_{n i, k}^{I}+\varepsilon_{n i, k}^{I I}\right) .
\end{aligned}
$$

specific import barriers in sector $k$ are given by: $m_{n, k}=-1 / \theta_{k}\left(D_{n, k}^{i m p}+D_{i, k}^{e x p}\right)$. By including a fixed-effect for both the importer and the exporter, $D_{i, k}^{e x p}$ and $D_{n, k}^{i m p}$ would have the same mirrored specification, exactly as $S_{i, k}$ and $S_{n, k}$. Therefore, the expedient makes very little sense from an econometric point of view. 
The equation is estimated by generalized least squares. The parameters of the variancecovariance matrix are inferred in a standard way, i.e. starting from the residuals $\widehat{\varepsilon}_{n i, k}$ of a preliminary OLS regression. The main diagonal of the matrix, along which the entries are $\theta_{k}^{2}\left(\sigma_{I, k}^{2}+\sigma_{I I, k}^{2}\right)$, is reconstructed by taking averages of $\widehat{\varepsilon}_{n i, k}^{2}$. The off-diagonal non-zero elements, namely $\theta_{k}^{2} \sigma_{I I, k}^{2}$, are estimated by averaging $\widehat{\varepsilon}_{n i, k} \widehat{\varepsilon}_{i n, k}$.

Notice that (12) allows for a direct estimation of parameter $\theta_{k}$, simply by taking the opposite in sign of the estimated trade elasticity to tariffs. It also allows for quantifying $\rho_{k}$ (i.e. the transport cost elasticity to distance) by taking the ratio between estimated coefficients on distance and tariffs; the same procedure applies for any other gravity variable.

It is worth mentioning that, in this study, the problem of zeros in trade data does not arise, as the sample is largely restricted (with respect to those typically used in gravity estimations) by the availability of sectoral data on tariff-rates and expenditure, the latter being necessary for the reconstruction of market-share data. For this reason, any observation for which even a single one of these variables is missing had to be left out. The resulting sub-sample always feature strictly positive volumes of trade, even when trade occurs between very small countries.

\subsection{GLS estimates of the sectoral trade elasticities}

The preliminary OLS regressions have remarkably high fits $\left(R^{2}\right.$ ranks -across sectors- from 0.90 to 0.95$)$ but the inclusion of several country-dummies makes this a poorly meaningful statistic. It is worth pointing out a significant degree of heteroskedasticity in residuals, as revealed by the Breusch-Pagan test: in all sectors, the null is rejected for any reasonable level of significance. The gravity-type equations for bilateral trade derived from this multi-sector extension of EK are affected by the same problem detected by Santos-Sylva and Tenreyro (2006) in the standard gravity equations à la Anderson and Van Wincoop (2003).

Table 1 reports the GLS estimates of equation (12), at least for the part concerning the influence of iceberg costs on trade. For each sector, the shape parameter of the efficiency distribution (which regulates the within-sector degree of technological heterogeneity among industries) is measured as the opposite in sign of the estimated coefficients on tariffs (reported as $\ln (\operatorname{tau})) .{ }^{15} \mathrm{~A}$ large dispersion in efficiency draws (i.e. a low value of $\theta_{k}$ ) implies that, in the sector of interest, comparative advantages exert a high pressure in favor of trading. A detailed description of the data used in this study can be found in Appendix A, where Tables A.1 and A.2 list labels used, respectively, for the 13 manufacturing sectors and the 51 countries (both

\footnotetext{
${ }^{15}$ Since tariffs might be driven by trade (as protection policies often go along with other types of reforms that might also affect trade), the main concern about estimating trade elasticities by using tariffs is that estimators employing tariff data may be affected by endogeneity and omitted variable bias. Nonetheless, the composition of the sample of countries used in this paper largely mitigates these flaws. Most of them are in fact OECD Members, and participate in custom unions or free trade areas (as the NAFTA or the EU) which nullify or significantly reduce the degree of discretion of each state in setting tariffs, vis-a-vis their different trading partners. In order to avoid the use of tariff rates in estimating trade elasticity for the whole tradable sector, Bekkers (2013) proposes an empirical strategy based on first-order Taylor approximations around the free trade equilibrium in a Melitz-type economy. This procedure delivers an alternative estimator for trade elasticity, which requires only data on import shares, distance and gross output. Nevertheless, the value of aggregate trade elasticity estimated by Bekkers turns out to be very close to that estimated in this paper, in the pooled regression shown in Appendix F.
} 
OECD and non-OECD) that have been considered in this exercise. According to the results, manufacturing sectors are characterized by very different trade elasticities, as already found by CP. Although a direct comparison between the result of the two papers is not possible (as datasets and sectoral classifications are different), the GLS estimates reported in Table 1 bear some resemblance to those obtained by $\mathrm{CP}$, at least in those sectors for which the two classifications offer a direct correspondence.

\section{Table 1: FGLS estimates of the sectral trade elasticities}

\begin{tabular}{|c|c|c|c|c|c|c|c|}
\hline \multirow[b]{2}{*}{ Sector } & \multirow[b]{2}{*}{ Variable } & \multirow{2}{*}{$\begin{array}{c}\text { Tariff barriers } \\
\ln (\text { tau) }\end{array}$} & \multicolumn{5}{|c|}{ Non-tariff barriers } \\
\hline & & & $\ln ($ distw) & borders & language & colony & legal \\
\hline \multirow{2}{*}{ FOOD } & $\begin{array}{l}\text { coeff. } \\
\text { std. error }\end{array}$ & $\begin{array}{r}\mathbf{- 1 . 9 5 1} \\
(0.399)\end{array}$ & $\begin{array}{r}\mathbf{- 0 . 8 8 5} \\
(0.009)\end{array}$ & $\begin{array}{l}\mathbf{0 . 8 3 3} \\
(0.259)\end{array}$ & $\begin{array}{l}\mathbf{0 . 4 7 6} \\
(0.234)\end{array}$ & $\begin{array}{l}\mathbf{0 . 9 7 9} \\
(0.294)\end{array}$ & $\begin{array}{l}\mathbf{0 . 4 6 3} \\
(0.136)\end{array}$ \\
\hline & effect on iceberg costs & - & 0.454 & -0.427 & -0.244 & -0.502 & -0.237 \\
\hline \multirow{2}{*}{ TXTL } & coeff. & -9.213 & -0.607 & $\mathbf{1 . 6 0 4}$ & $\begin{array}{l}\mathbf{0 . 9 4 6} \\
(0.256)\end{array}$ & $\mathbf{0 . 6 1 2}$ & $\begin{array}{l}\mathbf{0 . 0 2 4} \\
(0.161)\end{array}$ \\
\hline & effect on iceberg costs & - & 0.066 & -0.174 & -0.103 & -0.066 & -0.003 \\
\hline \multirow{2}{*}{ WOOD } & coeff. & $\begin{array}{r}-\mathbf{9 . 3 7 7} \\
(1.448)\end{array}$ & $\begin{array}{r}\mathbf{- 0 . 9 3 5} \\
(0.012)\end{array}$ & $\begin{array}{l}\mathbf{1 . 4 7 7} \\
(0.316)\end{array}$ & $\begin{array}{l}\mathbf{0 . 6 7 6} \\
(0.286)\end{array}$ & $\begin{array}{l}\mathbf{0 . 8 5 7} \\
(0.362)\end{array}$ & $\begin{array}{l}\mathbf{0 . 3 1 4} \\
(0.179)\end{array}$ \\
\hline & effect on iceberg costs & - & 0.100 & -0.157 & -0.072 & -0.091 & -0.034 \\
\hline \multirow{2}{*}{ PAPR } & $\begin{array}{l}\text { coeff. } \\
\text { std. error }\end{array}$ & $\begin{array}{r}\mathbf{- 1 0 . 8 2 2} \\
(1.633)\end{array}$ & $\begin{array}{r}\mathbf{- 0 . 8 8 7} \\
(0.011)\end{array}$ & $\begin{array}{l}\mathbf{1 . 4 4 9} \\
(0.312)\end{array}$ & $\begin{array}{l}\mathbf{0 . 8 4 4} \\
(0.266)\end{array}$ & $\begin{array}{l}\mathbf{0 . 9 2 8} \\
(0.348)\end{array}$ & $\begin{array}{l}\mathbf{0 . 5 6 5} \\
(0.164)\end{array}$ \\
\hline & effect on iceberg costs & - & 0.082 & -0.134 & -0.078 & -0.086 & -0.052 \\
\hline \multirow{2}{*}{ CHEM } & coeff. & $\begin{array}{r}-\mathbf{6 . 2 2 4} \\
(1.309)\end{array}$ & $\begin{array}{r}-\mathbf{- 0 . 6 8 0} \\
(0.010)\end{array}$ & $\begin{array}{l}\mathbf{1 . 4 0 3} \\
(0.272)\end{array}$ & $\begin{array}{l}\mathbf{0 . 3 6 5} \\
(0.268)\end{array}$ & $\begin{array}{l}\mathbf{0 . 7 5 1} \\
(0.311)\end{array}$ & $\begin{array}{l}\mathbf{0 . 5 4 1} \\
(0.152)\end{array}$ \\
\hline & effect on iceberg costs & - & 0.109 & -0.225 & -0.059 & -0.121 & -0.087 \\
\hline \multirow{2}{*}{ PLST } & $\begin{array}{l}\text { coeff. } \\
\text { std. error }\end{array}$ & $\begin{array}{r}-\mathbf{4 . 5 1 5} \\
(1.044)\end{array}$ & $\begin{array}{r}\mathbf{- 0 . 7 9 8} \\
(0.010)\end{array}$ & $\begin{array}{l}\mathbf{1 . 4 3 8} \\
(0.239)\end{array}$ & $\begin{array}{l}\mathbf{0 . 6 9 1} \\
(0.221)\end{array}$ & $\begin{array}{l}\mathbf{0 . 6 9 4} \\
(0.270)\end{array}$ & $\begin{array}{l}\mathbf{0 . 4 2 0} \\
(0.127)\end{array}$ \\
\hline & effect on iceberg costs & - & 0.177 & -0.318 & -0.153 & -0.154 & -0.093 \\
\hline \multirow{2}{*}{ MNRL } & $\begin{array}{l}\text { coeff. } \\
\text { std. error }\end{array}$ & $\begin{array}{r}-4.017 \\
(1.244)\end{array}$ & $\begin{array}{r}\mathbf{- 0 . 9 2 5} \\
(0.011)\end{array}$ & $\begin{array}{l}\mathbf{1 . 2 3 9} \\
(0.286)\end{array}$ & $\begin{array}{l}\mathbf{0 . 8 2 5} \\
(0.246)\end{array}$ & $\begin{array}{l}\mathbf{0 . 8 7 3} \\
(0.323)\end{array}$ & $\begin{array}{l}\mathbf{0 . 2 6 6} \\
(0.156)\end{array}$ \\
\hline & effect on iceberg costs & - & 0.230 & -0.308 & -0.205 & -0.217 & -0.066 \\
\hline \multirow{2}{*}{ BMTL } & $\begin{array}{l}\text { coeff. } \\
\text { std. error }\end{array}$ & $\begin{array}{r}\mathbf{- 1 0 . 1 6 2} \\
(1.859)\end{array}$ & $\begin{array}{r}\mathbf{- 0 . 7 2 3} \\
(0.013)\end{array}$ & $\begin{array}{l}\mathbf{1 . 7 9 1} \\
(0.376)\end{array}$ & $\begin{array}{l}\mathbf{1 . 3 8 6} \\
(0.375)\end{array}$ & $\begin{array}{l}\mathbf{0 . 2 8 4} \\
(0.425)\end{array}$ & $\begin{array}{l}\mathbf{0 . 4 9 2} \\
(0.236)\end{array}$ \\
\hline & effect on iceberg costs & - & 0.071 & -0.176 & -0.136 & -0.028 & -0.048 \\
\hline \multirow{2}{*}{ MTLP } & $\begin{array}{l}\text { coeff. } \\
\text { std. error }\end{array}$ & $\begin{array}{r}\mathbf{- 3 . 1 6 2} \\
(1.196)\end{array}$ & $\begin{array}{r}-\mathbf{0 . 8 6 2} \\
(0.010)\end{array}$ & $\begin{array}{l}\mathbf{1 . 4 1 9} \\
(0.237)\end{array}$ & $\begin{array}{l}\mathbf{0 . 8 2 9} \\
(0.230)\end{array}$ & $\begin{array}{l}\mathbf{0 . 8 0 3} \\
(0.279)\end{array}$ & $\begin{array}{l}\mathbf{0 . 1 8 4} \\
(0.126)\end{array}$ \\
\hline & effect on iceberg costs & - & 0.273 & -0.449 & -0.262 & -0.254 & -0.058 \\
\hline \multirow{2}{*}{ MCHN } & coeff. & $\begin{array}{r}-\mathbf{9 . 8 4 2} \\
(1.395)\end{array}$ & $\begin{array}{r}-\mathbf{0 . 6 1 3} \\
(0.009)\end{array}$ & $\mathbf{1 . 1 0 1}$ & $\mathbf{1 . 0 4 4}$ & $\mathbf{0 . 2 9 5}$ & $\mathbf{0 . 3 0 9}$ \\
\hline & effect on iceberg costs & - & 0.062 & -0.112 & -0.106 & -0.030 & -0.031 \\
\hline \multirow{2}{*}{ ELCT } & $\begin{array}{l}\text { coeff. } \\
\text { std. error }\end{array}$ & $\begin{array}{r}\mathbf{- 1 0 . 7 7 7} \\
(1.464)\end{array}$ & $\begin{array}{r}-\mathbf{- 0 . 6 0 5} \\
(0.011)\end{array}$ & $\begin{array}{l}\mathbf{1 . 1 5 0} \\
(0.263)\end{array}$ & $\begin{array}{l}\mathbf{0 . 9 9 7} \\
(0.270)\end{array}$ & $\begin{array}{l}\mathbf{0 . 5 6 8} \\
(0.334)\end{array}$ & $\begin{array}{l}\mathbf{0 . 0 6 4} \\
(0.159)\end{array}$ \\
\hline & effect on iceberg costs & - & 0.056 & -0.107 & -0.092 & -0.053 & -0.006 \\
\hline \multirow{2}{*}{ TRSP } & $\begin{array}{l}\text { coeff. } \\
\text { std. error }\end{array}$ & $\begin{array}{r}-\mathbf{2 . 7 5 7} \\
(1.036)\end{array}$ & $\begin{array}{r}-\mathbf{0 . 7 1 1} \\
(0.012)\end{array}$ & $\begin{array}{l}\mathbf{1 . 6 8 5} \\
(0.351)\end{array}$ & $\begin{array}{l}\mathbf{1 . 0 6 2} \\
(0.341)\end{array}$ & $\begin{array}{l}\mathbf{0 . 4 0 3} \\
(0.409)\end{array}$ & $\begin{array}{l}\mathbf{0 . 2 2 2} \\
(0.203)\end{array}$ \\
\hline & effect on iceberg costs & - & 0.258 & -0.611 & -0.385 & -0.146 & -0.080 \\
\hline \multirow{2}{*}{ NECL } & $\begin{array}{l}\text { coeff. } \\
\text { std. error }\end{array}$ & $\begin{array}{r}\mathbf{- 9 . 1 8 4} \\
(1.416)\end{array}$ & $\begin{array}{r}-\mathbf{0 . 7 1 6} \\
(0.012)\end{array}$ & $\begin{array}{l}\mathbf{1 . 0 8 5} \\
(0.317)\end{array}$ & $\begin{array}{l}\mathbf{1 . 8 0 5} \\
(0.297)\end{array}$ & $\begin{array}{l}\mathbf{0 . 0 7 3} \\
(0.362)\end{array}$ & $\begin{array}{l}\mathbf{0 . 2 2 2} \\
(0.179)\end{array}$ \\
\hline & effect on iceberg costs & - & 0.078 & -0.118 & -0.197 & -0.008 & -0.024 \\
\hline
\end{tabular}

In Table 1, sectoral trade elasticities range from slightly less than 2 up to almost 11, which is exactly the range identified in the literature for the value of trade elasticity at aggregate level. ${ }^{16}$ The food manufacturing sector (FOOD) is that featuring more dispersion

\footnotetext{
${ }^{16}$ Following two alternative methods (based on wage data and retail price data, respectively), EK originally identify a range between 3.60 and 12.86 for the value of aggregate trade elasticity, being 8.28 their preferred
} 
in industry efficiencies: the reason is probably that the consumption of these products is strongly affected by tastes, which allows for the coexistence, within this sector, of industries characterized by very different levels of productivity. A large dispersion in industry efficiencies is detected also in the sectors of transport equipment (TRSP) and fabricated metal products (MTLP). The latter, in particular, is a sector comprised of a wide range of products, mainly used as intermediate inputs: hence, it might make sense to ascribe the relatively low value of $\theta_{k}$ in this sector to its broad definition. ${ }^{17}$ In contrast, high values for $\theta_{k}$ have been estimated in sectors which mainly produce capital-goods, such as machinery (MCHN), or with high capital/technology intensity, such as the electrical equipment industries (ELCT). Other sectors, engaged in more traditional productions, such as textile (TXTL) or wood (WOOD), display relatively large values of $\theta_{k}$. With respect to the product categories manufactured in these sectors, taste is typically less influential and buyers are more willing to shift their demand in favor of the goods that are produced more efficiently.

Hence, the estimates reported in Table 1 seem to suggest a possible connection, within each sector, between the measure of technological heterogeneity among industries and the degree of substitutability among the goods produced by those industries. This substitutability, in turn, crucially depends on how narrowly or broadly one define the different product categories (i.e. the sectors) in which the whole space of manufacturing goods has been split. This clue is somewhat supported by the evidence coming from Imbs and Mejean (2009) and Chen and Novy (2012), who provide a pioneering investigation into the elasticities of substitution within the different product categories. ${ }^{18} \mathrm{~A}$ deeper investigation on the matter is desirable.

Looking at Table 1 , it is worth mentioning a negative correlation $(-0.4)$ between coefficients on tariffs and distance: the dampening effect of tariffs on trade is more important in sectors in which bilateral trade appears relatively less sensitive to distance. In other words, the selection operated by tariffs on both source and destination markets (which leads to the identification of exporting and surviving industries, respectively) is residual to that operated by distance. Given the interpretation of the trade elasticity to tariffs as a measure of within-sector dispersion in efficiencies, one may rephrase as follows: where industry efficiencies are less dispersed, comparative advantages become less effective, room for trade shrinks and distance turns out to be less important in shaping trade patterns.

This also provides an explanation for the rather uniform effect exerted by distance across manufacturing sectors. ${ }^{19}$ Although estimated coefficients on distance might be more

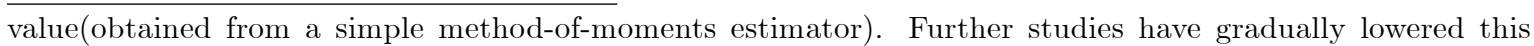
value: Alvarez and Lucas (2007) calibrated a value of 6.67, and Simonovska and Waugh (2011) subsequently identified a range from 2.47 to 4.42 , where 4 is their preferred value. More recent works, such as Buono and Lalanne (2012) or Bekkers (2013), advocate even lower values, always slightly below 3.

${ }^{17}$ Also the sectors of plastic (PLST) and chemical products (CHEM) display relatively low values of $\theta_{k}$, that are not far away from that estimated in the sector producing mineral products (MNRL), despite the very different levels of labor intensity featured by these sectors.

${ }^{18}$ Chen and Novy (2011), in particular, estimate the substitution elasticities across the 163 manufacturing industries, using the estimation approach pioneered by Feenstra (1994) and adapted by Broda and Weinstein (2006) and Imbs and Méjean (2009). As expected, they find that elasticities vary substantially across industries.

${ }^{19} \mathrm{~A}$ point for discussion is represented by the extent to which the quite homogeneous effect of distance on normalized trade-shares across sectors is related to a stardard result in trade literurate, that is, distance elasticity of aggregate trade flows (in levels) is always close to one in many gravity equations. The good news is that, given this uniformity in the estimated marginal effects, studies aimed at describing the relationship between geography and trade based on countrly level data (not disaggregated by sector) can provide useful 
heterogeneous across sectors when using a different dependent variable (i.e. trade flows instead of trade-shares), equation (12) clearly shows that the marginal effect of distance is always a combination of the within-sector dispersion in efficiency (i.e. $\theta_{k}$ ) and the marginal effect of distance on the non-tariff component of iceberg costs, namely $\rho_{k}$.

\section{Table 2: Interpretation of the regression coefficients}

Percentage change in the geometric mean of normalized trade-shares and non-tariff barriers, in reply to a $10 \%$ increase in tariff rates or distance (measured in $\mathrm{km}$ ), and marginal effects of gravity dummy-variables.

\begin{tabular}{|c|c|c|c|c|c|c|c|}
\hline \multirow[b]{2}{*}{ Sector } & \multirow[b]{2}{*}{ Variable } & \multirow{2}{*}{$\frac{\text { Tariff barriers }}{\ln (\text { tau })}$} & \multicolumn{5}{|c|}{ Non-tariff barriers } \\
\hline & & & $\ln ($ distw $)$ & borders & language & colony & legal \\
\hline \multirow{2}{*}{ FOOD } & normalized mkt-share & -0.170 & $-0.081 * * *$ & $1.300 * * *$ & $0.610 * *$ & 1.662 & 0.589 \\
\hline & non-tariff barriers & & 0.044 & -0.347 & -0.217 & -0.395 & -0.211 \\
\hline \multirow{2}{*}{ TXTL } & normalized mkt-share & -0.584 & $-0.056 * * *$ & $3.972 * * *$ & $1.574 * * *$ & $0.843 *$ & 0.024 \\
\hline & non-tariff barriers & & 0.006 & -0.160 & -0.098 & -0.064 & -0.003 \\
\hline \multirow{2}{*}{ WOOD } & normalized mkt-share & -0.591 & $-\mathbf{0 . 0 8 5} * * *$ & $3.378 * * *$ & $0.967 * *$ & $1.356 * * *$ & 0.369 \\
\hline & non-tariff barriers & & 0.010 & -0.146 & -0.070 & -0.087 & -0.033 \\
\hline \multirow{2}{*}{ PAPR } & normalized mkt-share & -0.643 & $-0.081 * * *$ & $3.258 * * *$ & $1.325 * * *$ & $1.530 * * *$ & $0.760 * * *$ \\
\hline & non-tariff barriers & & 0.008 & -0.125 & -0.075 & -0.082 & -0.051 \\
\hline \multirow{2}{*}{ CHEM } & normalized mkt-share & -0.447 & $-0.063 * * *$ & $3.068 * * *$ & 0.440 & $1.119 * * *$ & $0.718 * * *$ \\
\hline & non-tariff barriers & & 0.010 & -0.202 & -0.057 & -0.114 & -0.083 \\
\hline \multirow{2}{*}{ PLST } & normalized mkt-share & -0.350 & $-0.073 * * *$ & $3.210 * * *$ & $0.995 * * *$ & $1.002 * * *$ & $0.521 * * *$ \\
\hline & non-tariff barriers & & 0.017 & -0.273 & -0.142 & -0.143 & -0.089 \\
\hline \multirow{2}{*}{ MNRL } & normalized mkt-share & -0.318 & $-0.084 * * *$ & $2.451 * * *$ & $1.282 * * *$ & $1.394 * * *$ & $0.304 *$ \\
\hline & non-tariff barriers & & 0.022 & -0.265 & -0.186 & -0.195 & -0.064 \\
\hline \multirow{2}{*}{ BMTL } & normalized mkt-share & -0.620 & $-0.067 * * *$ & $4.996 * * *$ & $2.997 * * *$ & 0.328 & $0.635 * *$ \\
\hline & non-tariff barriers & & 0.007 & -0.162 & -0.127 & -0.028 & -0.047 \\
\hline \multirow{2}{*}{ MTLP } & normalized mkt-share & -0.260 & $-0.079 * * *$ & $3.132 * * *$ & $1.292 * * *$ & $1.232 * * *$ & 0.202 \\
\hline & non-tariff barriers & & 0.026 & -0.362 & -0.231 & -0.224 & -0.056 \\
\hline \multirow{2}{*}{ MCHN } & normalized mkt-share & -0.609 & $-0.057 * * *$ & $2.008 * * *$ & $1.842 * * *$ & 0.344 & $0.361 * *$ \\
\hline & non-tariff barriers & & 0.006 & -0.106 & -0.101 & -0.030 & -0.031 \\
\hline \multirow{2}{*}{ ELCT } & normalized mkt-share & -0.642 & $-0.056 * * *$ & $2.158 * * *$ & $1.709 * * *$ & 0.765 & 0.066 \\
\hline & non-tariff barriers & & 0.005 & -0.101 & -0.088 & -0.051 & -0.006 \\
\hline \multirow{2}{*}{ TRSP } & normalized mkt-share & -0.231 & $-0.066 * * *$ & $4.391 * * *$ & $1.891 * * *$ & 0.496 & 0.248 \\
\hline & non-tariff barriers & & 0.025 & -0.457 & -0.320 & -0.136 & -0.077 \\
\hline \multirow{2}{*}{ NECL } & normalized mkt-share & -0.583 & $-0.066 * * *$ & $1.959 * * *$ & $5.082 * * *$ & 0.075 & 0.249 \\
\hline & non-tariff barriers & & 0.007 & -0.111 & -0.178 & -0.008 & -0.024 \\
\hline \multicolumn{8}{|c|}{ * Significant at $95 \%$} \\
\hline \multicolumn{8}{|c|}{$\begin{array}{l}* \text { * Significant at } 97.5 \% \\
* * * \text { Significant at } 99 \%\end{array}$} \\
\hline
\end{tabular}

To facilitate the economic interpretation of the results shown in Table 1, it might be useful to apply a convenient transformation, which leads to the values reported in Table 2. In the latter, the first column reports the relative change in the geometric mean of the dependent variable (i.e. the normalized trade-share $\ln X_{n i, k}^{\prime} / X_{n n, k}^{\prime}$ ) due to a $10 \%$ increase in tariff rates. In the food sector, for instance, the estimated effect is a $17 \%$ contraction of guidance, as approximate. 
bilateral trade-shares. Likewise, the column $\ln$ (distw) refers to the effect of a $10 \%$ increase in the number of kilometers between trading partners. In the sector of chemical products (CHEM), for instance, this increase in distance leads to a $1 \%$ rise in the value of non-tariff barriers and a $6.3 \%$ reduction in normalized trade-shares. Not surprisingly, non-tariff barriers are very sensitive to distance when considering imports (or exports) of foodstuffs, while they are rather inelastic in sectors in which geography, in general, plays a minor role (as it results from estimated coefficients on the other gravity variables).

According to Table 2, territorial contiguity always plays a significant role in determining trade-shares, and particularly in the sector of basic metals (BMTL) and transport equipment (TRSP) products. In general terms, the fact of speaking the same language appears to be relatively less important. When singling out the effect of common language on iceberg costs, a large effect is observed in the sectors of food, transport equipment and fabricated metal products, while a relatively small-scale effect is detected in the sectors of wood, paper and chemical products. Moreover, common legal origin is not significant as a predictor for trade in most of the product categories (and when it is, the effect on market-shares is anyhow virtually negligible) and also the presence of past colonial ties poorly explain bilateral trade-shares, even though they induce a large reduction in non-tariff barriers in the sectors manufacturing food and fabricated metal products. Thus, the econometric exercise shown in his paragraph does not illuminate on their role in determining trade patters, which remains controversial in the literature. ${ }^{20}$

\section{Estimation of the scale parameters}

Manufacturing sectors exhibit very different trade elasticities and therefore very different values of $\theta_{k}$. The assumption of a common $\theta$ across sectors, usually made in many previous extensions of EK, is likely to bias also the estimates of the parameter $T_{i k}$, which governs the scale of the distribution.

An accurate estimate of the latter (across both countries and sectors) is the key to a proper reconstruction of the structure of comparative advantages. This section outlines a new procedure to infer the values of $T_{i k}$ for each country-sector pair, starting from easily obtainable data on production and trade, in tune with most of the literature built on EK. These values pin down the relative average efficiency of the various countries across the different manufacturing sectors. Yet, the average efficiencies estimated in this paper differ from those computed, among others, by Shikher (2011) and Costinot et al. (2012), as they are obtained not only by relaxing the assumption of common trade elasticities, but also by following a new procedure, which makes use of model-based measures of relative prices.

\footnotetext{
${ }^{20}$ Santos Silva and Tenreyro (2006) find significant discrepancies when exploring the role of colonial heritage in the standard gravity equations à la Anderson and Van Wincoop (2003). Their Poisson regressions (based on a pseudo-maximum likelihood method) suggest that they have no role in determining bilateral flows. In contrast, either the Tobit and the non-linear squares estimators return substantial effects, but opposite in sign.
} 


\subsection{Price equations}

In the EK framework, it is easy to compute sectoral price indices, because they only depend on the price distribution of the goods actually produced by domestic industries in each country.

Consider first the simpler case of autarky. Since utility function is CES with respect to individual goods within each sector, the price index in sector $k$ and country $i$ turns out to be:

$$
p_{i, k ; a}=\left[\int_{j \in k} p_{i, k ; a}^{1-\sigma_{k}}(j) d j\right]^{\frac{1}{1-\sigma_{k}}} .
$$

Subscript $a$ emphasizes that prices entering the above equation are those prevailing under autarky.

Plugging equations (5) and (1) into the CES price-aggregator and using the Fréchet assumption, one can derive a set of $K$ non-linear equations for any $i=1, \ldots, N$ :

$$
p_{i, k ; a}=\mu_{k} w_{i}^{\beta_{k}} T_{i, k}^{-1 / \theta_{k}} \prod_{h=1}^{K} p_{i, h ; a}^{\left(1-\beta_{k}\right) \eta_{k h}}
$$

where $\mu_{k}$ is a collection of constant terms. As equation (13) clearly reveals, a fixed-point problem in prices is nested into the above set of non-linear equations, as a result of the loop generated by the inclusion of intermediate goods among inputs.

Consider now the case of an open economy. Due to the equilibrium property of EK, $p_{i, k}$ can be computed by singling out (and integrating across) only those goods actually produced by local manufacturers in country $i$ and sector $k$ :

$$
p_{i, k ; o}=\left[\int_{D_{i k} \cup E_{i k}} p_{i, k ; o}^{1-\sigma_{k}}(j) d j\right]^{\frac{1}{1-\sigma_{k}}} .
$$

Here the subscript $o$ stands for open economy: prices entering the above equation are those prevailing under trade openness. The domain of integration is now represented by $D_{i k} \cup E_{i k}$, the union between the set of exporters and non-exporters in sector $k$, respectively. ${ }^{21}$ Their union spans the whole set of industries surviving foreign competition in country $i$.

The open economy counterpart of the autarky price equation (13) is then:

$$
p_{i, k ; o}=\mu_{k} w_{i}^{\beta_{k}} T_{i, k}^{-1 / \theta_{k}}\left(\frac{X_{i, k}}{X_{i i, k}}\right)^{-1 / \theta_{k}} \prod_{h=1}^{K} p_{i, h ; o}^{\left(1-\beta_{k}\right) \eta_{k h}},
$$

where $X_{i, k} / X_{i i, k}$ is the inverse of country $i$ 's home market-share in sector $k$, given by the ratio between the country's total spending in goods from sector $k$, namely $X_{i, k}$, and the value of production sold domestically, namely $X_{i i, k}$. Generalizing the result obtained by Finicelli et al. $(2009,2012)$ related to a standard EK model with only one sector, this ratio is the extent to which efficiency distribution in country $i$ and sector $k$ shifts upwards after opening

\footnotetext{
${ }^{21}$ In formal terms: $z_{i, k}(j) \in D_{i, k}=\left\{z_{i, k}(j) \in \mathbb{R}_{+} ; z_{i, k}(j) c_{i, k} / c_{n, k} d_{i n, k} \leq z_{i, k}(j) \leq z_{n, k}(j) c_{i, k} d_{n i, k} / c_{n, k}\right\}$. This means that set $D_{i, k}$ collects all industries from country $i$ and sector $k$ that (provided their level of efficiency and unit-cost of production and iceberg costs incurred by their competitors) fulfill the survival condition but not the export condition. On the other hand, set $E_{i, k}$ includes any surviving industry which satisfies the export condition at least for one foreign market; set $E_{i, k}$ can be formally defined as $\bigcup_{n=1, \ldots N}^{n \neq i} E_{i, k}^{n}$, where $z_{i, k}(j) \in E_{i, k}^{n}=\left\{z_{i, k}(j) \in \mathbb{R}_{+} ; z_{i, k}(j)>z_{n, m}(j) c_{i, k} d_{n i, k} / c_{n, k}\right\}$.
} 
to trade. In other words, in an open economy the distribution of industry efficiencies in sector $k$ and country $i$ has scale $T_{i, k} \cdot\left(X_{i, k} / X_{i i, k}\right)$, where $X_{i, k} / X_{i i, k} \geqslant 1$ by construction. ${ }^{22}$

\subsection{Relative prices and average efficiencies}

In order to infer the scale parameters $T_{i, k}$ (and the countries' relative average efficiencies across sectors) from bilateral trade data, this paper outlines an original methodology which is different from those employed by Shikher (2011) and Costinot, Donaldson and Komunjer (2012, CDK hereinafter). The former depicts a pure Ricardian model, where equations simplify as labor is the only input and relative prices are measured based on price-data observations at plant level. ${ }^{23}$ The latter retrieves the relative values of $T_{i, k}$ by combining bilateral trade equations, similar to (4), with a simplified version of the output equation implied by the model and then fitting a subset of the model to the data. By following the procedure shown below, this paper avoids the use of simplified versions of the equations used in the model, and also the imposition of any long-run equilibrium condition.

As a starting point to illustrate the analytical steps, consider equation (6) where $i$ is the importer and $n$ the exporter. By normalizing by the importer's home sales delivers, the equation becomes:

$$
\frac{X_{i n, k}}{X_{i i, k}}=\frac{T_{n, k}}{T_{i, k}}\left(\frac{c_{n, k}}{c_{i, k}}\right)^{-\theta_{k}} d_{i n, k}^{-\theta_{k}}
$$

Taking logs and specifying the unit cost of an input bundle, relative states of technology turn out to be:

$$
\ln \frac{T_{i, k}}{T_{n, k}}=\ln \frac{X_{i i, k}}{X_{i n, k}}-\theta_{k} \ln d_{i n, k}-\beta_{k} \theta_{k} \ln \frac{w_{n}}{w_{i}}-\left(1-\beta_{k}\right) \theta_{k} \sum_{h=1}^{K} \eta_{k h} \ln \frac{p_{n, h}}{p_{i, h}} .
$$

To get a quantification of both relative states of technology and prices, one can combine equation (15) with (14) and, then, use estimated coefficients on tariffs, distance and other gravity variables in equation (12) to carefully reconstruct iceberg costs incurred by any source when shipping to a given destination across the different manufacturing sectors. ${ }^{24}$

\footnotetext{
${ }^{22}$ Let $Z_{i, k ; o}$ be the efficiency distribution across all national industries in sector $k$ that are still engaged in production after trade liberalization in country $i$. As also stressed by Costinot et al. (2012), $Z_{i, k ; o}$ can be derived analytically from the fundamental distribution of industry efficiencies, namely $Z_{i, k}$, which is the one that would be observed under autarky, when all domestic industries are engaged in production. By following Finicelli et al. (2013), it can be proved that, when $Z_{i k} \sim \operatorname{Frèchet}\left(T_{i k}, \theta_{k}\right)$, then $Z_{i k, o}$ is still Fréchetdistributed, with parameters $T_{i k} \cdot\left(X_{i, k} / X_{i i, k}\right)$ and $\theta_{k}$. Given the properties of the Fréchet, $Z_{i, k ; o}$ first-order stochastically dominates $Z_{i, k}$, as the scale multiplier $X_{i, k} / X_{i i, k}$ is always greater than (or, at least, equal to) one, by construction. To understand how one can derive the distribution of $Z_{i k, o}$ as a conditional, starting from the corresponding distribution of $Z_{i k}$, see Costinot et. al. (2012), Finicelli et al. (2013) and Bolatto and Sbracia (2013).

${ }^{23}$ Costinot, Komunjer and Donaldson collect firms-level data on prices, interpreting the myriad of products per industry as varieties of the same good. Then, they aggregate them to form an overall producer-price index for each industry, using output data. Finally, they take the inverse of the resulting price index as the empirical counterpart of the observed productivity in an open economy. By combining these measures with trade data, they infer the values of $T_{i k} / T_{n k}$, i.e. the states of technology for each country-sector pair, expressed in relative terms with respect to a bechmark country $n$ (given the bilateral nature of trade flows).

${ }^{24}$ On the basis of the specification of iceberg costs $d_{n i, k}$ used in Section 3.2, data on tariff rates, log-distance and other gravity dummies can be combined with estimated values for coefficients $\left\{\xi_{r, k}\right\}_{r=1}^{4}$ and $\rho_{k}$ (coming from Table 1) in order to quantify $d_{n i, k}$ across sectors, sources and destinations.
} 
The whole procedure is based on the relative price equations derived in the previous paragraph. By taking logs of equation (14) and considering the corresponding equation for country $n$ (henceforth denoting the benchmark country, which is the US), relative prices in sector $k$ turn out to be:

$$
\ln \frac{p_{i, k}}{p_{n, k}}=\beta_{k} \ln \frac{w_{i}}{w_{n}}-\frac{1}{\theta_{k}} \ln \frac{T_{i, k}}{T_{n, k}}-\frac{1}{\theta_{k}} \ln \frac{X_{i, k} / X_{i i, k}}{X_{n, k} / X_{n n, k}}+\left(1-\beta_{k}\right) \sum_{h=1}^{K} \eta_{k h} \ln \frac{p_{i, h}}{p_{n, h}} .
$$

By plugging (15) into the above equation, relative prices can be written as:

$$
\ln \frac{p_{i, k}}{p_{n, k}}=-\frac{1}{\theta_{k}}\left(\ln X_{i i, k}-\ln X_{i n, k}\right)+\ln d_{i n, k}-\frac{1}{\theta_{k}} \ln \frac{X_{i, k} / X_{i i, k}}{X_{n, k} / X_{n n, k}} .
$$

Prices in equation (16) can be directly measured by relying on the estimates of $\theta_{k}$ and $d_{i n, k}$ derived from the results shown in Table 1. Moreover, the value of parameters $\alpha_{k}$, $\eta_{k h}$ and $\beta_{k}$ can be easily derived from statistical databases or national account statistics. Thus, relative prices in the above equation are directly quantifiable and can be plugged into equation (15) in order to derive the relative states of technology, namely $T_{i, k} / T_{n, k}$, and finally the relative average efficiencies, given by: $E\left(Z_{i, k}\right) / E\left(Z_{n, k}\right)=\left(T_{i, k} / T_{n, k}\right)^{1 / \theta_{k}}$, provided that $E\left(Z_{i, k}\right)=\left(T_{i, k}\right)^{1 / \theta_{k}} \Gamma\left(\left(\theta_{k}-1\right) / \theta_{k}\right)$ is the first moment of the efficiency distribution in country $i$ and sector $k$ under the Fréchet assumption.

Table 3 reports, for each economy, the resulting average efficiency (relative to the US) across the different product categories. These measures pin down the Ricardian comparative advantage at sector level, which determine, in turn, the patterns of trade and specialization. Since relative average efficiencies are obtained from model-based measures of relative prices, they might seem to share the same limitation of the standard measure of productivity, i.e. the real output per unit of input. As it is well-known, the latter is a reliable statistic to the extent that output deflators used in its computation have been properly measured. Nevertheless, unlike CDK, relative prices in this paper are not derived from price-data observations, but inferred from trade and gravity data and they are therefore somewhat endogenous. ${ }^{25}$

Appendix A provides a description of the data used in this study, performed for 13 manufacturing and 20 sectors20 countries (listed in Tables A.1 and A.3, respectively).

Table 3 shows that Germany and Italy have a comparative advantage (with respect to the US) in producing machinery and non-metallic mineral products, and Japan in producing transport equipment and fabricated metal products. East-European and Latin American countries, as well as Portugal, are generally at the bottom of the productivity rankings. In the wood sector, Scandinavian countries present the highest average efficiency; Germany is the most efficient producer of chemical products and Japan is leading in the sector of plastic and rubber products. Notice that entries are above one for a large number of countries in the sector of non-metallic mineral products, revealing a comparative disadvantage for the US in this kind of productions. The efficiency gap between the US and Japan, Germany, Italy and France is also considerable in the sector of fabricated metal products. Finally, Japan

\footnotetext{
${ }^{25}$ Given the nominal wage level in each country, relative mean efficiencies are fully reflected into the relative prices, despite real cross-sectional variation in producer-prices is likely to reflect more than productivity differences in practice. The strand of literature built on the Heckscher-Ohlin model, for instance, suggests that this variation is due to differences in factor-intensity across countries and sectors.
} 
and the US have a strong comparative advantage (vis-à-vis the other countries) in producing machinery and electrical apparatus, appliances and supplies.

Table 3: Trade-revealed measures of relative average efficiency

\begin{tabular}{|c|c|c|c|c|c|c|c|c|c|c|c|c|c|c|c|}
\hline & & XTL & OOD & APR & CHEM & PLST & MNRL & BMTL & MTLP & MCHN & ELTR & TRSP & NECL & mean & td dev \\
\hline USA & 000 & 000 & 1.000 & 1.000 & 1.000 & 1.000 & 1.000 & 1.000 & 1.000 & 1.000 & 1.000 & 1.000 & 1.000 & 1.000 & - \\
\hline AR & & 696 & 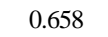 & 0.604 & 0.6 & & 0.694 & 0.686 & & & 0.601 & & 0.565 & & 160 \\
\hline BRA & 547 & 77 & 0 & 0.473 & 562 & 0.398 & 0.538 & 0.616 & 0.408 & 456 & 0.498 & 523 & .558 & & .065 \\
\hline CAN & 1.1 & 0.825 & 0.926 & 0.797 & & 0.846 & 0.833 & 0.897 & 0.747 & 0.835 & 0.886 & 744 & 0.768 & & 109 \\
\hline CZE & 0.605 & 0.459 & 0.526 & 0.432 & 0.483 & 0.338 & 0.679 & 0.529 & 0.512 & 0.411 & 0.442 & 0.529 & 0.398 & .488 & 0.090 \\
\hline DEU & 0.924 & 0.861 & 1.038 & 0.992 & 1.160 & 0.920 & 1.389 & 1.041 & 1.429 & 0.969 & 0.948 & 1.048 & 1.014 & 1.056 & 173 \\
\hline ESP & 0.7 & 0.771 & 0.832 & 0.705 & 25 & 0.563 & 1.056 & 0.816 & 0.844 & 0.692 & 0.700 & 0.371 & 0.658 & .737 & 0.161 \\
\hline FIN & & 771 & 1.014 & 904 & & 664 & 110 & 941 & .812 & 06 & 0.907 & 51 & .710 & & .191 \\
\hline FRA & 918 & 0.858 & 0. & 0.852 & 975 & 0.709 & 1.319 & 0.902 & 1.102 & 0.877 & 0.902 & 0.908 & 0.829 & 932 & 0.147 \\
\hline GBR & & 333 & 0. & 0.856 & 0.954 & 0.754 & 1.150 & 0.895 & 0.957 & 0.893 & 0.870 & 695 & 0.864 & 8 & .125 \\
\hline GRC & 0.569 & 0.667 & 0.698 & 0.609 & 0.736 & 0.532 & 0.781 & 0.814 & 0.490 & 0.653 & 0.633 & 0.307 & 0.792 & .637 & .141 \\
\hline ITA & & 0.922 & 0.809 & 0.817 & 0.906 & 0.875 & 1.267 & 870 & 1.344 & 821 & 0.846 & 815 & 0.792 & 898 & 0.198 \\
\hline JPN & 0.895 & 0.996 & 0.855 & 1.065 & 1.038 & 1.174 & 1.292 & 1.068 & 1.499 & 082 & 1.041 & .257 & 0.902 & .090 & 180 \\
\hline KOR & 0.664 & 0.716 & 0.715 & 0.727 & 0.781 & 0.653 & 0.604 & 0.791 & 0.808 & 0.680 & 0.690 & 0.810 & 0.572 & & .076 \\
\hline MEX & & 0.506 & & 0.506 & 0.645 & 0.445 & 0.407 & 883 & 0.486 & 0.429 & 0.487 & 0.785 & 0.517 & & 0.192 \\
\hline NOR & 1.180 & 0.776 & 1.064 & 0.937 & 0.867 & 0.619 & 1.196 & 0.944 & 0.707 & 0.915 & 0.897 & 0.730 & 0.797 & 0.894 & 0.175 \\
\hline POL & & 0.404 & 0.487 & 0.398 & 0.510 & 0.338 & 0.561 & 0.508 & 0.374 & 0.432 & 0.454 & 0.348 & 0.427 & 0.445 & 0.073 \\
\hline PRT & 0.550 & 0.559 & 0.610 & 0.528 & 0.605 & 0.347 & 0.885 & 0.598 & 0.480 & 0.541 & 0.514 & 0.248 & 0.560 & 0.540 & 0.147 \\
\hline SWE & 593 & 0.744 & 1.036 & 0.973 & 0.828 & 0.647 & 1.027 & 0.910 & 0.902 & 0.908 & 0.848 & 0.922 & 0.809 & 857 & 0.134 \\
\hline TUR & 0.715 & 0.592 & 0.569 & 0.482 & 0.589 & 0.455 & 0.650 & 0.637 & 0.442 & 0.509 & 0.537 & 0.458 & 0.498 & 0.549 & 0.085 \\
\hline & & 0.712 & & & & & 0.918 & & 0.784 & & & & 0.686 & & \\
\hline std dev & 0.226 & 0.170 & 0.199 & 0.215 & 0.188 & 0.235 & 0.298 & 0.174 & 0.346 & 0.217 & 0.200 & 0.282 & 0.182 & 0.226 & \\
\hline
\end{tabular}

NOTE: Entries are expressed as countries' average efficiency with respect to the US. Therefore, they must be interpreted as the relative value of the first moment of the sectoral distribution of industry efficiencies (the value of the US being normalized to 1 within each sector).

Finally, it might be interesting to compare the relative average efficiencies estimated under heterogeneous trade elasticities, with the corresponding values that one obtains by imposing common trade elasticities across sectors. Appendix F reports the result of a pooled regression, in which equations (12) are regressed simultaneously across sectors, by imposing that coefficients $\theta_{k}, \rho_{k}$ and $\left\{\xi_{r, k}\right\}_{r=1}^{4}$ are all sector-invariant. The estimated value of the aggregate trade elasticity, namely $\theta$, is 2.63 , which is also the measure of the overall dispersion in efficiency across all manufacturing industries. This value has been used to estimate countries' average efficiencies, vis-a-vis the US, across the different sectors under the assumption of common trade elasticity. In Figure 1, these estimates, obtained by following the same procedure described in this Section, are plotted against their corresponding values in Table 3 , derived for the estimates of the sector-specifc trade elasticities. In both Figure 1a and Figure 1b, the shadow points correspond to the combinations between the two measures in the various country-sector pairs, while the solid line is the 45 degrees line. Relative average efficiencies obtained under common trade elasticity are somehow proportional to those estimated under heterogeneous trade elasticities, but there is a substantial difference when one makes a comparison between, for instance, the textile sector and that producing transport 
equipment. Points highlighted in Figure 1a correspond to the combinations referred to the textile and apparel sector (TXTL), in which estimated trade elasticity is 9.21 (see Table 1). Those highlighted in Figure 1b refers to the sector of transport equipment (TRSP), in which estimated trade elasticity is 2.76 . As the former are much more dispersed with respect to the 45 degrees lines, it stands to reason that the assumption of common elasticity across sectors induces a larger bias, the larger is the difference between the sector-specific size of the trade elasticity and the value at which the aggregate/common elasticity is set (in this case, 2.63).

\section{Figure 1: Relative average efficiencies (RAE) under heterogenous and common trade elasticities, by sector}
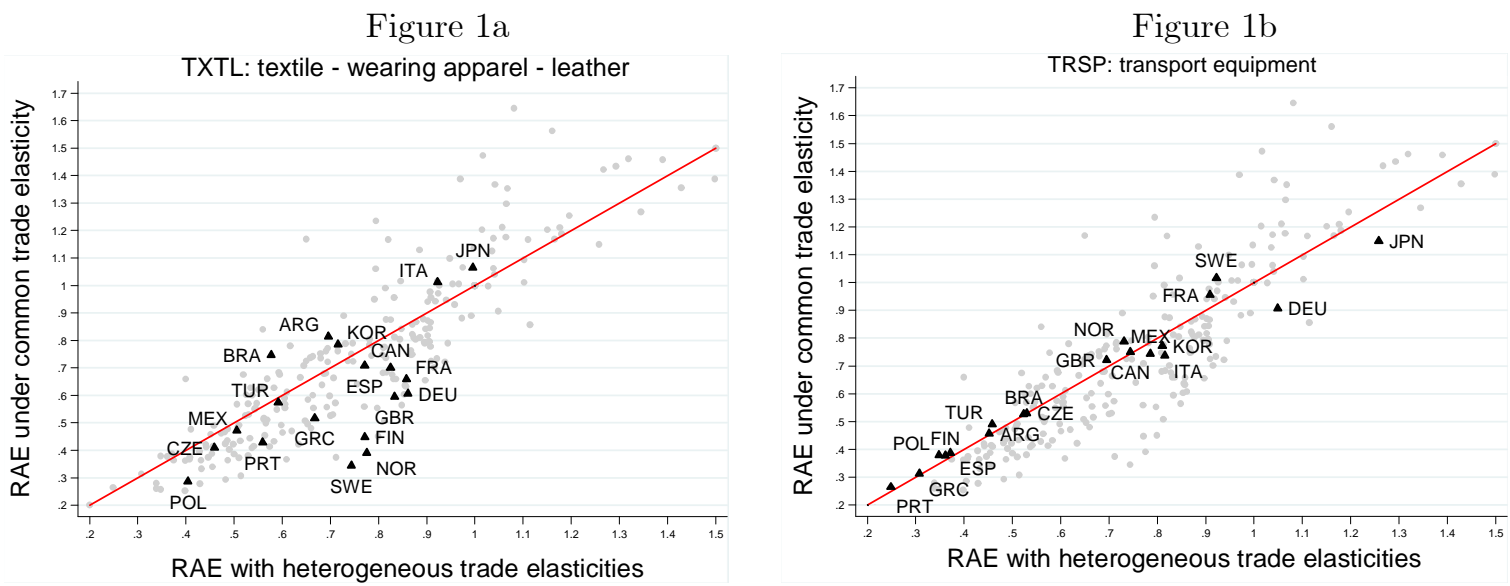

\section{Gains from trade}

A more careful assessment of the overall effect of trade on welfare necessarily calls for a more sophisticated analysis, which goes beyond the simple notion of average efficiency. When considering the relative values of the states of technology, namely $T_{i, k} / T_{n, k}$, or the (relative) first moments of the efficiency distributions, namely $E\left(Z_{i, k}\right) / E\left(Z_{n, k}\right)$, one can only perform a simple sector-by-sector analysis. In fact, sectoral distributions of industry efficiencies are mutually independent by assumption, even when they refer to the same country. As a consequence, the measures of average efficiency estimated across different manufacturing sectors for a given country can not be combined to determine the country's global level of productivity.

To overcome this problem and to develop a study of countries' aggregate productivity based on sectoral data, this paper advocates the use of alternative measures. The present Section makes use of labor productivity indices, quantified both at aggregate and sector level on the basis of available data on wages and model-based measures of relative prices. 


\subsection{A labor productivity analysis}

This paper pursues a standard approach for quantifying labor productivity indices. As shown in Appendix E, in each country and sector, an aggregate production function can be derived from the identity: $p_{i, k} Q_{i, k}=w_{i} L_{i, k}+\sum_{h=1}^{K} p_{i, h} M_{i, k h}$. Since intermediate goods are nonprimary factors, the output at sector level, namely $Q_{i, k}$, can be written as a linear function in the amount of labor used by all industries comprised in sector $k$ under any trade regime. This amount, denoted as $L_{i, k}$, necessarily corresponds to a given fraction of country $i$ 's labor endowment. While the latter is equal, in an open economy, to sector $k$ 's share in the total manufacturing value-added, namely $s_{i, k}$, sectoral shares in total employment are pinned down by preferences under autarky, as the Cobb-Douglas coefficients in the aggregate utility function directly set the relative size of the various manufacturing sectors. ${ }^{26}$

In both a closed and an open economy, labor productivity indices correspond to the proportionality constant between sectoral output and the amount of labor employed in production, namely $A_{i, k}$. Thus, labor productivity in country $i$ and sector $k$ is given by:

$$
A_{i, k}=\frac{1}{\beta_{k}} \frac{w_{i}}{p_{i, k ; o}} \text {, provided that } Q_{i, k}=A_{i, k} L_{i, k} \text { and } L_{i, k}=s_{i, k} L_{i},
$$

while, in a closed economy, it is:

$$
A_{i, k}=\frac{1}{\beta_{k}} \frac{w_{i}}{p_{i, k ; a}}, \text { provided that } Q_{i, k}=A_{i, k} L_{i, k} \text { and } L_{i, k}=\alpha_{k} L_{i} .
$$

Basically, index $A_{i, k}$ can be seen as a measure of real wage paid in country $i$, adjusted for the relative price of sector $k$ with respect to the rest of the economy. The countries' labor productivities are then easy to quantify at sector level, given the model-based measures of price deflators derived in Section 4.2 and provided that wage data are largely available for many countries. Moreover, as they are built on sectoral price-indices (which allow for quantifying them only in relation to a benchmark country), these labor productivity indices inherit all information embodied in the relative prices, including the linkages among the $K$ sectors. $^{27}$

Table 4 reports the values of the $A_{i, k}$ index for the same 19 countries listed in Table 3 and across the same 13 sectors, assuming the US as benchmark. The table also reports the aggregate labor productivity at country level, namely $A_{i}$. The construction of the latter is crucial to get insights into how sectoral labor productivities merge and determine the overall welfare level attained by each country.

\footnotetext{
${ }^{26}$ In a closed economy, the overall spending coincides with the national income, since the value of domestic production necessarily corresponds to the demand from local consumers: $Y_{i}=w_{i} L_{i}=X_{i}$. This equality holds even at sectoral level: $Y_{i, k}=X_{i, k}=\alpha_{k} X_{i}$. Since the value-added in industry $k$ is given by $w_{i} L_{i, k}$, the amount of labor allocated to sector $k$ is then $L_{i, k}=\alpha_{k} L_{i}$. Thus, labor allocation across sectors follows from the distribution of spending across the different product categories and turns out to be common to all countries, given the assumption of homothetic preferences.

${ }^{27}$ As equations (13) and (14) clearly reveal, any price index $p_{i, k}$ is a function of the sector-specific state of technology, namely $T_{i, k}$. At the same time, $p_{i, k}$ also depends on the price index for intermediate goods, which is a combination of all prices $\left\{p_{i, h}\right\}_{h=1}^{K}$. It follows that $p_{i, k}$ is actually a complex function of all the country $i$ 's states of technologies across sectors. Thereby, when running the analysis in terms of $A_{i, k}$, rather than $E\left(Z_{i, k}\right)$, sector $k$ can be contextualized in the rest of the economy, in view of all the input-output connections between this sector and the others. Furthermore, notice that all the variation measured in sectoral labor productivities after trade liberalization is fully reflected into the variation of the corresponding relative prices.
} 
Table 4: Relative labor productivities in the open economy, by sector

\begin{tabular}{|c|c|c|c|c|c|c|c|c|c|c|c|c|c|c|c|}
\hline & FOOD & TXTL & WOOD & PAPR & CHEM & PLST & MNRL & BMTL & MTLP & MCHN & ELTR & TRSP & NEC & $\begin{array}{c}\text { Simple } \\
\text { Average } \\
\end{array}$ & $\begin{array}{l}\text { Aggr. Labor } \\
\text { Productivity }\end{array}$ \\
\hline USA & 1.000 & 1.000 & 1.000 & 1.000 & 1.000 & 1.000 & 1.000 & 1.000 & 1.000 & 1.000 & 1.000 & 1.000 & 1.000 & 1.000 & 1.000 \\
\hline ARG & 0.575 & 0.307 & 0.301 & 0.278 & 0.276 & 0.213 & 0.367 & 0.287 & 0.259 & 0.270 & 0.272 & 0.165 & 0.292 & 0.297 & 0.294 \\
\hline BRA & 0.128 & 0.167 & 0.159 & 0.143 & 0.140 & 0.112 & 0.195 & 0.173 & 0.128 & 0.133 & 0.138 & 0.119 & 0.172 & 0.147 & 0.139 \\
\hline CAN & 1.164 & 0.672 & 0.764 & 0.645 & 0.730 & 0.708 & 0.726 & 0.765 & 0.673 & 0.726 & 0.752 & 0.746 & 0.661 & 0.749 & 0.780 \\
\hline CZE & 0.175 & 0.136 & 0.164 & 0.133 & 0.132 & 0.113 & 0.296 & 0.152 & 0.201 & 0.142 & 0.135 & 0.169 & 0.124 & 0.159 & 0.152 \\
\hline DEU & 1.128 & 1.091 & 1.247 & 1.114 & 1.523 & 1.181 & 1.819 & 1.346 & 1.859 & 1.223 & 1.114 & 1.367 & 1.211 & 1.325 & 1.285 \\
\hline ESP & 0.447 & 0.486 & 0.561 & 0.441 & 0.515 & 0.371 & 0.813 & 0.545 & 0.592 & 0.469 & 0.452 & 0.218 & 0.465 & 0.490 & 0.446 \\
\hline FIN & 0.477 & 0.632 & 0.915 & 0.757 & 0.717 & 0.551 & 1.023 & 0.836 & 0.732 & 0.774 & 0.779 & 0.398 & 0.705 & 0.715 & 0.652 \\
\hline FRA & 0.881 & 0.795 & 0.943 & 0.753 & 0.948 & 0.679 & 1.446 & 0.879 & 1.092 & 0.873 & 0.840 & 0.854 & 0.823 & 0.908 & 0.885 \\
\hline GBR & 0.559 & 0.757 & 0.969 & 0.737 & 0.904 & 0.702 & 1.162 & 0.855 & 0.912 & 0.879 & 0.814 & 0.635 & 0.857 & 0.826 & 0.774 \\
\hline GRC & 0.258 & 0.349 & 0.373 & 0.321 & 0.393 & 0.315 & 0.492 & 0.486 & 0.316 & 0.391 & 0.379 & 0.263 & 0.440 & 0.367 & 0.345 \\
\hline ITA & 0.428 & 0.750 & 0.646 & 0.662 & 0.788 & 0.761 & 1.255 & 0.767 & 1.234 & 0.748 & 0.716 & 0.842 & 0.680 & 0.791 & 0.714 \\
\hline JPN & 0.978 & 1.035 & 0.834 & 1.176 & 1.178 & 1.316 & 1.506 & 1.247 & 1.780 & 1.276 & 1.168 & 1.407 & 0.984 & 1.222 & 1.185 \\
\hline KOR & 0.345 & 0.388 & 0.400 & 0.436 & 0.434 & 0.372 & 0.358 & 0.456 & 0.505 & 0.408 & 0.397 & 0.397 & 0.354 & 0.404 & 0.401 \\
\hline MEX & 0.516 & 0.174 & 0.260 & 0.190 & 0.219 & 0.189 & 0.160 & 0.190 & 0.218 & 0.172 & 0.183 & 0.359 & 0.198 & 0.233 & 0.243 \\
\hline NOR & 1.245 & 0.801 & 1.124 & 0.885 & 0.897 & 0.652 & 1.288 & 1.025 & 0.778 & 0.955 & 0.897 & 0.863 & 0.905 & 0.947 & 0.954 \\
\hline POL & 0.118 & 0.104 & 0.126 & 0.103 & 0.115 & 0.087 & 0.200 & 0.122 & 0.113 & 0.119 & 0.117 & 0.077 & 0.119 & 0.117 & 0.111 \\
\hline PRT & 0.191 & 0.205 & 0.239 & 0.204 & 0.205 & 0.138 & 0.466 & 0.246 & 0.211 & 0.229 & 0.212 & 0.138 & 0.235 & 0.224 & 0.204 \\
\hline SWE & 0.450 & 0.857 & 1.045 & 0.911 & 0.840 & 0.638 & 1.053 & 0.888 & 0.887 & 0.907 & 0.850 & 0.956 & 0.878 & 0.858 & 0.796 \\
\hline TUR & 0.239 & 0.204 & 0.202 & 0.170 & 0.183 & 0.159 & 0.287 & 0.228 & 0.184 & 0.197 & 0.201 & 0.170 & 0.213 & 0.203 & 0.199 \\
\hline mean & 0.542 & 0.521 & 0.593 & 0.530 & 0.586 & 0.487 & 0.785 & 0.605 & 0.667 & 0.573 & 0.548 & 0.534 & 0.543 & 0.578 & 0.556 \\
\hline std dev & 0.369 & 0.331 & 0.375 & 0.354 & 0.404 & 0.368 & 0.509 & 0.385 & 0.522 & 0.384 & 0.357 & 0.422 & 0.344 & & \\
\hline
\end{tabular}

As pointed out by Demidova and Rodríguez-Clare (2009), to avoid the inconvenience of summing up "apples and oranges", physical quantities of the goods have to be summed up as they enter the utility function, that is, in a symmetric way. ${ }^{28}$

Since global utility is Cobb-Douglas in the overall amount of goods consumed by the $K$ different sectors, country $i$ 's global output in manufacturing turns out to be: $Q_{i}=$ $=\prod_{k=1}^{K} Q_{i, k}^{\alpha_{k}}$, where aggregate production $Q_{i}$ is a linear function of the country's labor endowment. With a very simple algebra, it can be shown that aggregate productivity in an open economy (where $L_{i, k}=s_{i, k} L_{i}$ ) is:

$$
A_{i}=\prod_{k=1}^{K}\left(A_{i, k} s_{i, k}\right)^{\alpha_{k}}
$$

Aggregate productivity is then a weighted geometric mean (where weights are given by the sectoral expenditure shares $\alpha_{k}$ ) of the sectoral labor productivities, augmented by the corresponding share that each sector represents in total manufacturing employment and valueadded. Notice that equation (17) mixes up sectoral labor productivities in order to account,

\footnotetext{
${ }^{28}$ The point is to consider quantities that enter the utility function, namely $C(j)$, as efficiency units, instead of physical quantities. In other words, for each individual good the raw quantity, denoted as $\widetilde{C}(j)$, is weighted with a preference parameter or a quality measure $\nu_{j}$. Then, outputs are aggregated consistently with preferences: in this case, with CES at sectoral level -over the continuum of goods- and then with Cobb-Douglas across the $K$ different sectors. As Demidova and Rodríguez-Clare posit, productivity measures obtained in this way are immune to unit changes: "in equilibrium, a change in units would imply a change in $\nu_{j}$ but leave $C(j)$ unchanged".
} 
somehow, for the sectoral composition of each economy. ${ }^{29}$

In Table 4, Germany and Japan display values of $A_{i}$ greater than the US. This is not surprising, as both countries usually lead productivity rankings in manufactures. It could be interesting to compare these aggregate labor productivity indices with the nominal wages in manufacturing, reported in the last column of Table 4. In 11 out of 19 countries, the wage levels (relative to the US) turns out to be lower when expressed in real terms (i.e. in the form of aggregate labor productivity). This set of 11 countries includes Northern European countries and the UK. On the other hand, countries with a clear manufacturing vocation, such as Germany, Italy and Japan, are better off when wages are expressed in real terms. The two groups of countries offset each other: the overall cross-country dispersion in relative wages is roughly the same when considering nominal and real values. As the model entirely focuses on manufacturing, countries that are more specialized in the tertiary sector of the economy are likely to be penalized in this kind of comparison.

\section{Figure 2: Labor productivity indices vs average efficiencies, by sector}
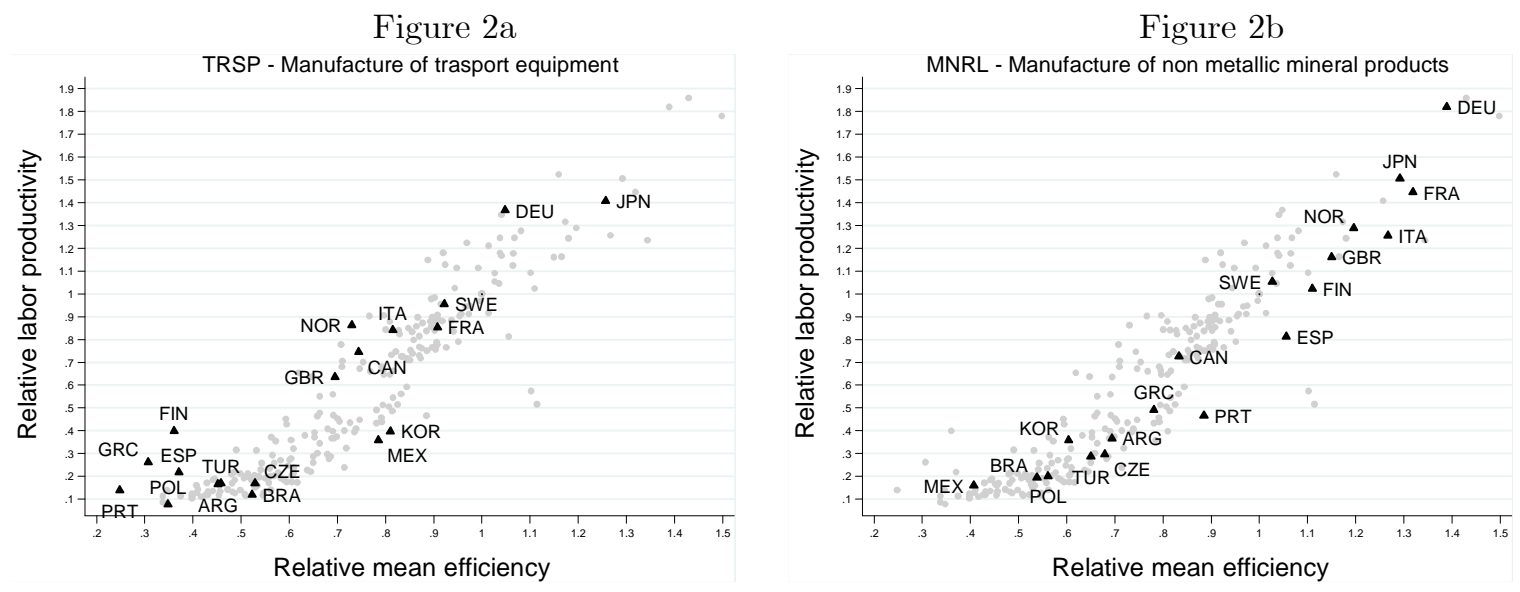

Finally, Figure 2 shows a clear proportionality between the labor productivity indices of Table 4 and the average efficiencies of Table 3. The shadow points refers to all possible combination between the two measure for the various country-sector pair. The points highlighted in Figure 2a are the combination (by country) of the two measures of productivity in the sector of non-metallic mineral products (MNRL), whereas those in Figure 2b refer to the sector of transport equipment (TRSP). The latter are more dispersed than the former: as the sector of transport equipment features a lower value-added share in total output, the labor productivity index in this sector is more affected by the average efficiencies attained in other sectors of the economy, and the linkage between the two measures becomes weaker. The sector producing non metallic mineral products features a lower requirement of inputs

\footnotetext{
${ }^{29}$ In this model, value-added shares $s_{i k}$ reveal country $i$ 's specialization pattern to the extent that they differ from the corresponding expenditure shares, namely $\alpha_{k}$. In particular, the ratio $s_{i k} / \alpha_{k}$ can be used as a proxy of a proper specialization index. When $s_{i k} / \alpha_{k}>1(<1)$, country $i$ is specialized (de-specialized) in producing goods from sector $k$ : the share of the latter in total employment and total value-added rises after the removal of trade barriers, as country $i$ starts producing for the export market.
} 
form other sectors, thus in that the sector labor productivity index is more related to the sector-specific average efficiency among individual producers.

\subsection{Gains from trade in terms of productivity}

In trade literature, quantifying the benefits of international trade is undoubtedly one of the most common exercises. As a common practice, gains from trade are defined (and measured) as the increase in countries' level of welfare that follows from a trade liberalization.

In a standard version of EK, with only one sector, real wage is directly proportional to the aggregate average efficiency; this implies an obvious connection between welfare gains and (aggregate) productivity gains from trade. In contrast, in a multi-sector environment the link is less obvious because of the twine created by inter-sectoral links.

In this study based on sectoral data, the possibility of working with labor productivity indices allows for switching easily from the sector to the aggregate level, and vice-versa. Thus, by quantifying gains from trade in terms of labor productivity rather than welfare, one can perform a more detailed analysis of the effects of trade openness. First, by using the sector-specific estimates of trade elasticity from Section 3, it is possible to precisely measure gains from trade in each sector of manufacturing. Then, it is also possible to explain how sectoral gains merge together and determine the global outcome at country level; that is, the gain which is quantifiable according to the well-established approach proposed by Arkolakis, Costinot and Rodriguez-Clare (2012, ACR hereinafter). ${ }^{30}$

To perform this analysis, one has to quantify sectoral labor productivities in the closed economy, which entails computing the autarky prices. This task can be accomplished by numerically solving the difference equation generated by the log-transformation of equations (13) and (14):

$$
\ln \frac{p_{i, k ; a}}{p_{i, k ; o}}=\frac{1}{\theta_{k}} \ln \frac{X_{i, k}}{X_{i i, k}}+\left(1-\beta_{k}\right) \sum_{h=1}^{K} \eta_{k h} \ln \frac{p_{i, h ; a}}{p_{i, k ; o}} .
$$

The above equation represents a system of $K$ equations in $K$ unknowns (i.e. the autarky prices $p_{i, k ; a}$ ), which entails a fixed-point problem in $p_{i, k ; a}$. The numerical solutions of the system allows for a quantification of the relative change in price-indices and therefore in sectoral labor productivities resulting from trade liberalization. Labor productivity gains from trade are reported, by country and sector, in Table 5: for instance, the US labor productivity in the food sector (FOOD) is $5.2 \%$ higher in an open economy than in autarky. Analogously, labor productivity observed in the machinery sector (MCHN) in Turkey is $21.7 \%$ greater than its corresponding value in case of autarky. For some of the most peripheral countries, benefits

\footnotetext{
${ }^{30}$ Arkolakis, Costinot and Rodriguez-Clare (2012)prove that, in many quantitative models of international trade (including EK; Melitz, 2003; Krugman, 1980 and Argminton, 1969), welfare gains from trade, namely $\widehat{W}_{i}$, can always be computed according to the formula: $\widehat{W}_{i}=\left(X_{i} / X_{i i}\right)^{1 / \beta \theta}$. This result is remarkable because (i) it applies to models based on very different assumptions, both in terms of market structure and preferences, and (ii) it makes use of two sufficient statistics, namely the home market-share $\left(X_{i} / X_{i i}\right.$, which is data) and the trade elasticity parameter $\theta$, both computed at aggregate level. As trade elasticities are sector-specific in this paper, ACR's approach has to be modified in order to compute gains at country level, in the absence of a clear correspondence between the vector of sectoral trade elasticities $\left\{\theta_{k}\right\}_{k=1}^{K}$ and the resulting value of $\theta$ at aggregate level. The presence of parameter $\beta$ reflects the "magnification effect", generated by the inclusion of intermediate goods among the inputs. A conventional measure for $\beta$, used also in this paper, is 0.33 , while $\beta=1$ whenever intermediate goods are not accounted for.
} 
from trade turn out to be striking, especially for some product categories. As a general statement, productivity gains are lower in the larger economies and higher in the smaller economies, in line with predictions of traditional trade theory.

Table 5: Sectoral gains from trade in terms of labor productivity

\begin{tabular}{|c|c|c|c|c|c|c|c|c|c|c|c|c|c|c|}
\hline & FOOD & TXTL & WOOD & PAPR & CHEM & PLST & MNRL & BMTL & MTLP & MCHN & ELTR & TRSP & NECL & $\begin{array}{c}\text { simple } \\
\text { average }\end{array}$ \\
\hline USA & 0.052 & 0.122 & 0.042 & 0.074 & 0.260 & 0.060 & 0.055 & 0.214 & 0.116 & 0.071 & 0.154 & 0.226 & 0.039 & 0.114 \\
\hline ARG & 0.043 & 0.078 & 0.097 & 0.155 & 0.492 & 0.134 & 0.076 & 0.447 & 0.269 & 0.185 & 0.393 & 0.431 & 0.194 & 0.230 \\
\hline BRA & 0.033 & 0.034 & 0.037 & 0.062 & 0.236 & 0.050 & 0.028 & 0.147 & 0.098 & 0.081 & 0.144 & 0.163 & 0.026 & 0.088 \\
\hline CAN & 0.175 & 0.214 & 0.062 & 0.260 & 0.849 & 0.171 & 0.154 & 0.723 & 0.397 & 0.203 & 0.432 & 0.750 & 0.117 & 0.347 \\
\hline CZE & 0.179 & 0.298 & 0.094 & 0.370 & 1.812 & 0.430 & 0.179 & 0.929 & 0.600 & 0.288 & 0.665 & 0.590 & 0.076 & 0.501 \\
\hline DEU & 0.177 & 0.390 & 0.088 & 0.187 & 0.601 & 0.144 & 0.109 & 0.474 & 0.230 & 0.133 & 0.323 & 0.330 & 0.070 & 0.250 \\
\hline ESP & 0.134 & 0.153 & 0.073 & 0.192 & 0.636 & 0.177 & 0.075 & 0.576 & 0.270 & 0.187 & 0.443 & 0.831 & 0.151 & 0.300 \\
\hline FIN & 0.195 & 0.333 & 0.094 & 0.243 & 1.038 & 0.228 & 0.098 & 0.830 & 0.406 & 0.185 & 0.505 & 1.821 & 0.286 & 0.482 \\
\hline FRA & 0.173 & 0.224 & 0.097 & 0.198 & 0.660 & 0.152 & 0.118 & 0.522 & 0.244 & 0.166 & 0.317 & 0.303 & 0.145 & 0.255 \\
\hline GBR & 0.224 & 0.266 & 0.105 & 0.223 & 0.813 & 0.170 & 0.115 & 0.692 & 0.308 & 0.225 & 0.462 & 0.521 & 0.167 & 0.330 \\
\hline GRC & 0.230 & 0.206 & 0.103 & 0.347 & 1.336 & 0.336 & 0.131 & 1.200 & 0.618 & 0.318 & 0.920 & 2.492 & 0.069 & 0.639 \\
\hline ITA & 0.184 & 0.090 & 0.048 & 0.150 & 0.470 & 0.109 & 0.065 & 0.397 & 0.161 & 0.105 & 0.257 & 0.569 & 0.054 & 0.205 \\
\hline JPN & 0.067 & 0.083 & 0.043 & 0.044 & 0.148 & 0.031 & 0.021 & 0.077 & 0.044 & 0.026 & 0.063 & 0.034 & 0.032 & 0.055 \\
\hline KOR & 0.119 & 0.082 & 0.059 & 0.113 & 0.323 & 0.062 & 0.050 & 0.243 & 0.129 & 0.086 & 0.210 & 0.073 & 0.118 & 0.128 \\
\hline MEX & 0.078 & 0.159 & 0.067 & 0.237 & 0.881 & 0.329 & 0.104 & 0.812 & 0.563 & 0.272 & 0.629 & 0.604 & 0.061 & 0.369 \\
\hline NOR & 0.126 & 0.533 & 0.166 & 0.348 & 2.041 & 0.406 & 0.177 & 1.298 & 0.638 & 0.313 & 0.708 & 0.890 & 0.316 & 0.612 \\
\hline POL & 0.096 & 0.312 & 0.076 & 0.241 & 0.945 & 0.195 & 0.118 & 0.701 & 0.422 & 0.219 & 0.475 & 0.605 & 0.114 & 0.347 \\
\hline PRT & 0.272 & 0.223 & 0.097 & 0.356 & 1.370 & 0.354 & 0.134 & 1.463 & 0.572 & 0.332 & 0.951 & 2.490 & 0.154 & 0.674 \\
\hline SWE & 0.258 & 0.802 & 0.135 & 0.335 & 2.128 & 0.338 & 0.188 & 0.856 & 0.413 & 0.244 & 0.689 & 0.477 & 0.274 & 0.549 \\
\hline TUR & 0.083 & 0.125 & 0.093 & 0.220 & 0.727 & 0.171 & 0.077 & 0.695 & 0.398 & 0.217 & 0.530 & 0.720 & 0.230 & 0.330 \\
\hline mean & 0.145 & 0.236 & 0.084 & 0.218 & 0.888 & 0.202 & 0.104 & 0.665 & 0.345 & 0.193 & 0.464 & 0.746 & 0.135 & \\
\hline
\end{tabular}

Entries are expressed as the relative increase in labor-productivity indices that follows from trade openness with respect to autarky levels.

The cross-sector average of the productivity gains, displayed (by country) in the last column of Table 5, have a purely statistical relevance. A more meaningful measure of the global gain for each country can be derived starting from the autarky counterpart of equation (17), which combines the $K$ sectoral productivities of country $i$ according to weights that are no longer $s_{i, k}$, but $\alpha_{k}$. Under autarky, country $i$ 's labor productivity in manufacturing is then: $A_{i ; a}=\prod_{k=1}^{K}\left(\alpha_{k} A_{i, k ; a}\right)^{\alpha_{k}}$. Thus, the overall productivity gains from trade for country $i$, namely $\widehat{A_{i}}$, are given by: ${ }^{31}$

$$
\widehat{A_{i}}=\frac{A_{i ; o}}{A_{i ; a}}=\prod_{k=1}^{K}\left(\frac{A_{i, k ; o}}{A_{i, k ; a}} \frac{s_{i, k}}{\alpha_{k}}\right)^{\alpha_{k}} .
$$

Within each country, the global productivity gain depends on $(i)$ gains computed at sector level and (ii) the change induced in the sectoral composition of the economy, captured by ratios $s_{i k} / \alpha_{k}$.

\footnotetext{
${ }^{31}$ In the formulas entailing a comparison between labor productivities in the open and closed economy, subscripts $o$ and $a$ are used again to distinguish the different values attained by a given variable under the two trade regimes.
} 
Consider now the hypothetical case in which trade openness does not induce any change in the sectoral composition of the economy with respect to the case of autarky. This could be due, for instance, to rigidities or frictions on the labor markets, which prevent any reallocation of workers (or other resources) across sectors. ${ }^{32}$ In this scenario, each sector would preserve the same share of employment as under autarky and the ratio $s_{i, k} / \alpha_{k}$ would be one for each $k=1, \ldots, K$. The overall productivity gains in country $i$ would be:

$$
\left.\widehat{A_{i}}\right|_{s_{i, k}=\alpha_{k}}=\prod_{k=1}^{K}\left(\frac{A_{i, k ; o}}{A_{i, k ; a}}\right)^{\alpha_{k}} .
$$

Hence, the simple weighted geometric mean of the sectoral gains computed for a given country $i$ provides a measure of the country's gains from trade which only arise from reallocations within sectors. Thus, by comparing the simple weighted geometric mean of the sectoral gains, namely $\left.\widehat{A_{i}}\right|_{s_{i, k}=\alpha_{k}}$, with the actual value of the gains, namely $\widehat{A_{i}}$ (i.e. the weighted geometric mean of the gains which accounts for specialization), one may assess the relative importance of the within sector reallocations to the global benefit that country $i$ obtains thanks to trade openness. This, in turn, translates into an evaluation of the relative contribution of the two forms of reallocations, between and within sectors.

Table 6 summarizes the overall gains from trade computed for each of the 20 countries of interest, and those obtained under the restriction $s_{i k}=\alpha_{k}$. Findings suggest that the simple weighted geometric mean of the sectoral gains ranges from $76.2 \%$ up to $88.4 \%$ of the global productivity gain computed at country level, when also changes in the sectoral composition of the economy are taken into account. In other words, within-sector reallocations are by far the most important component of the productivity gains from trade. This is in keeping with the empirical evidence, according to which "much of world-trade is between countries with similar factor endowments, and trade between similar countries is largely intra-industry in character: that is, it consists of two-way trade in similar products" (Krugman, 1981).

While it is not surprising that benefits mainly come from reallocations within sectors, it is worth mentioning that the relative contribution of the latter is relatively higher in the developed, rather than developing countries. Hence, small economies are likely to receive larger benefits from changing their sectoral composition with respect to the case of autarky. Even this result can be somehow accommodated by the traditional trade theory. Of course, the relative contribution of reallocations between and within sectors may depend on the number of sectors in which manufacturing is split, and on how broadly or narrowly defined they are. Nonetheless, when investigating reallocation processes induced by trade, it makes sense to define manufacturing sectors in such a way that each sector includes sufficiently homogenous product categories, with (sufficiently) heterogeneous categories being part of different sectors. In this respect, the level of homogeneity of the various product categories may be defined by considering the features of the production functions overlying their manufacturing, particularly in terms of their factor intensities.

As workers reallocation among similar production activities, say motorcycles and cars manufacturing, may represent a minor issue in the real world, much more relevant and problematic is the reallocation that takes place across very different productions, such as those

\footnotetext{
${ }^{32}$ One reason might be the existence of prohibitive costs in shifting labor units across industries pertaining to different manufacturing sectors: in that case, workers could only move across industries comprised in the sector in which they are originally employed.
} 
of transport equipment and textile products, for instance. That is the kind of reallocations which is the most interesting to analyze. The classification used in this paper, as well as those used by CDK or CP, appear suitable for performing a study on this topic, which is getting more and more relevant in the current economic debate.

\section{Table 6: Decomposition of the labor productivity gains}

\begin{tabular}{|c|c|c|c|c|c|}
\hline \multirow[b]{2}{*}{ label } & \multirow[b]{2}{*}{ country } & \multirow{2}{*}{$\frac{\text { simple average }}{\operatorname{mean}\left(A_{i k, o} / A_{i k, a}\right)}$} & \multirow{2}{*}{$\frac{\text { overall gains }}{\Delta \mathbf{A}_{\mathrm{i}}=\mathbf{A}_{\mathrm{i}, \mathrm{o}} / \mathrm{A}_{\mathrm{i}, \mathrm{a}}}$} & \multicolumn{2}{|c|}{ within-reallocations } \\
\hline & & & & $\begin{array}{c}\text { size of the } \\
\text { effect }\end{array}$ & $\begin{array}{c}\% \text { on } \\
\text { overall gain }\end{array}$ \\
\hline FRA & France & 0.255 & 0.301 & 0.266 & 88.4 \\
\hline DEU & Germany & 0.250 & 0.297 & 0.261 & 87.9 \\
\hline GBR & United Kingdom & 0.330 & 0.394 & 0.346 & 87.7 \\
\hline KOR & Korea & 0.128 & 0.152 & 0.130 & 86.0 \\
\hline JPN & Japan & 0.055 & 0.067 & 0.057 & 85.5 \\
\hline USA & United States & 0.114 & 0.137 & 0.115 & 83.8 \\
\hline CAN & Canada & 0.347 & 0.411 & 0.343 & 83.4 \\
\hline ITA & Italy & 0.205 & 0.260 & 0.214 & 82.1 \\
\hline SWE & Sweden & 0.549 & 0.631 & 0.517 & 81.9 \\
\hline ESP & Spain & 0.300 & 0.356 & 0.290 & 81.2 \\
\hline CZE & Czech Rep. & 0.501 & 0.583 & 0.467 & 80.1 \\
\hline POL & Poland & 0.347 & 0.404 & 0.321 & 79.4 \\
\hline BRA & Brazil & 0.088 & 0.111 & 0.087 & 78.9 \\
\hline PRT & Portugal & 0.674 & 0.759 & 0.595 & 78.4 \\
\hline NOR & Norway & 0.612 & 0.675 & 0.525 & 77.8 \\
\hline FIN & Finland & 0.482 & 0.545 & 0.424 & 77.8 \\
\hline TUR & Turkey & 0.330 & 0.375 & 0.290 & 77.5 \\
\hline GRC & Greece & 0.639 & 0.725 & 0.558 & 77.0 \\
\hline ARG & Argentina & 0.230 & 0.260 & 0.198 & 76.3 \\
\hline MEX & Mexico & 0.369 & 0.417 & 0.318 & 76.2 \\
\hline & mean & 0.340 & 0.393 & 0.393 & 81.4 \\
\hline
\end{tabular}

NOTE: Entries are expressed as the relative change in labor-productivity (at country level) between the open and closed-economy case.

Finally, it could be interesting to compare, for each country, gains computed by using sectoral data and trade elasticity estimates with gains computed by using aggregate data and following the well-established approach proposed by ACR. In Figure 3, the aggregate labor productivity gains in Table 5 are plotted against the welfare gains quantified according to ACR, using a two different values for the aggregate trade elasticity.

In Figure 3a, the aggregate trade elasticity is set at 6.67, the value calibrated by Alvarez and Lucas (2006). In Figure 3b, the aggregate elasticity is set at 4, according to the findings of Simonovska and Waugh (2011). Particularly in the latter case, welfare and labor productivity gains are surprisingly very close to each other, particularly in countries characterized by small gains from trade (in some cases there is virtually no difference between the two measures). A bigger discrepancy can be noticed when considering economies that gain relatively more from trade (typically the more peripheral countries). Thus, the two measures of gains from trade tend to diverge in economies that change relatively more their sectoral composition after opening to trade. 
Figure 3 conveys a double message. First, the overall dispersion in industry efficiencies is likely to be large in models with a unique continuum of all tradeable goods. Hence, low values of parameter $\theta$ (e.g. 4, the value used in Figure 3) are preferable as they lead to outcomes which are more consistent with those obtainable by using sector-level data. Secondly, modelbased measures of the gains from trade (derived from the "quantitative" models) are more accurate and consistent when they refer to the larger and more productive economies. In smaller and more peripheral countries, the size of the gains appears to be more sensitive to the value of the parameters and to the kind of data used for their quantification.

\section{Figure 3: Welfare gains (à la ACR) vs labor productivity gains}

Figure $3 \mathrm{a}, \theta=6.67$

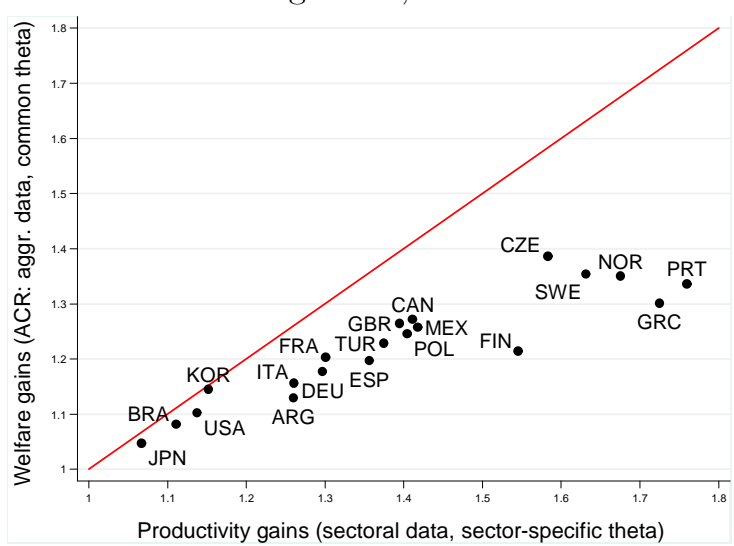

Figure $3 \mathrm{~b}, \theta=4$

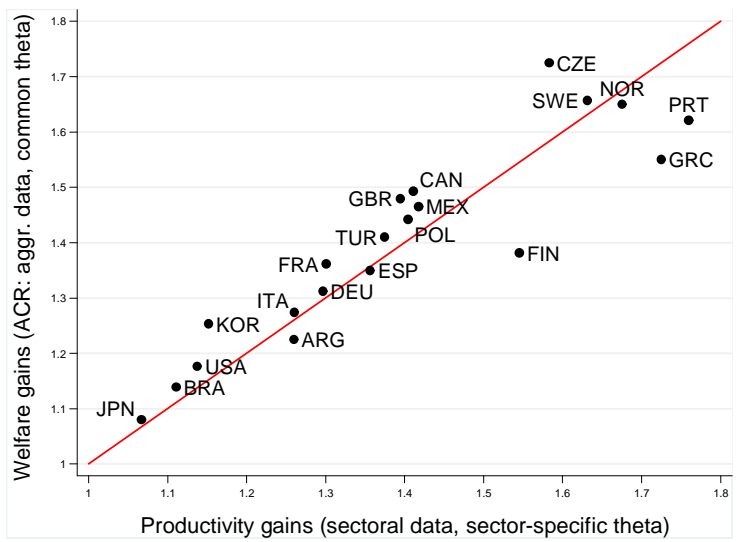

\section{Counterfactuals}

This section discusses a counterfactual exercise which yields important policy implications. Starting from the estimates obtained in previous sections, this study evaluates the effects of a country-and-sector specific technology shock. In particular, it assumes a $10 \%$ increase in the parameter reflecting the state-of-the-art technology in country $i$ and sector $h$, namely $T_{i h}$, and computes economic equilibrium for country $i$ by solving a system of non linear equations for wage and sectoral price indices, market-shares and employment-shares. The experiment is repeated for any sector $h=1, \ldots, K$. With this counterfactual study, one can replicate (and quantify) the effects at the country level generated by a policy aimed at enhancing growth in one specific sector (for instance, by focusing R\&D investments in that sector, considered as strategic for some reason).

\subsection{Methodology}

Regardless of the sector where it occurs, any technology shock spreads to the rest of the economy via an intermediate goods channel. For the sake of simplicity, consider a simplified two-country world with trade balance, where the home-country $i$ deals with $n$, standing for 
the rest-of-the-world. This allows for characterizing the home-country as a small economy, in such way that any shock occurring in $i$ does not affect the value of macro-economic variables in country $n$. In the counterfactual scenario that follows from a $10 \%$ increase in the value of $T_{i h}$, the economic equilibrium in country $i$ is fully described by this system of $4 K+1$ equations in $4 K+1$ unknowns:

$$
\begin{aligned}
& \frac{p_{i, k}^{\prime}}{p_{i, k}}=\left(\frac{1-\pi_{i i, k}}{1-\pi_{i i, k}^{\prime}}\right)^{-1 / \theta_{k}} \\
& \left(\frac{p_{i, k}^{\prime}}{p_{i, k}}\right)^{-\theta_{k}}=\frac{\pi_{i i, k}}{\pi_{i i, k}^{\prime}} \frac{\pi_{n i, k}^{\prime}}{\pi_{n i, k}} \frac{1-\pi_{n i, k}}{1-\pi_{n i, k}^{\prime}} \\
& \frac{p_{i, k}^{-\theta_{k}}-\left(p_{i, k}^{\prime}\right)^{-\theta_{k}}}{\gamma_{k}^{\theta_{k}}}=\frac{T_{i, k}}{w_{i}^{\beta_{k} \theta_{k}}} \prod_{h=1}^{K} p_{i, h}^{\eta_{k h}\left(\beta_{k}-1\right) \theta_{k}}-\frac{T_{i, k}^{\prime}}{\left(w_{i}^{\prime}\right)^{\beta_{k} \theta_{k}}} \prod_{h=1}^{K}\left(p_{i, h}^{\prime}\right)^{\eta_{k h}\left(\beta_{k}-1\right) \theta_{k}} ; \\
& w_{i}\left[\frac{s_{i, k}}{\alpha_{k}}-\pi_{i i, k}\right] \pi_{n i, k}^{\prime}=w_{i}^{\prime}\left[\frac{s_{i, k}^{\prime}}{\alpha_{k}}-\pi_{i i, k}^{\prime}\right] \pi_{n i, k} ; \\
& \sum_{k=1}^{K} s_{i, k}^{\prime}=1,
\end{aligned}
$$

where $k=1, \ldots, K$ and where the unknowns are given by the $(K \mathrm{x} 1)$ vectors collecting the value of $p_{i k}^{\prime}, \pi_{i i, k}^{\prime}, \pi_{n i, k}^{\prime}$ and $s_{i, k}^{\prime}$ for each $k$, plus the new level of wages in country $i$, namely $w_{i}^{\prime}$, which adjusts in order to ensure full employment. Let $p_{i k}^{\prime}$ denote the after-shock price-index in sector $k$ and country $i$, while $\pi_{i i, k}^{\prime}$ and $\pi_{n i, k}^{\prime}$ are the new shares that country $i$ represents in sector $k$, in destination markets $i$ and $n$, respectively. Finally, $s_{i, k}^{\prime}$ is the employment-share of sector $k$ which reflects the new sectoral composition of economy $i$ after the sector-specific productivity shock (which rises $T_{i k}$ to $T_{i, k}^{\prime}=1.1 \cdot T_{i, k}$ for $k=h$, leaving $T_{i, k}^{\prime}=T_{i k}$ for any $k \neq h)$.

By solving numerically the system of non linear equations, one can generate the aggregate results which are shown in the next paragraph. Appendix G illustrates the analytical steps needed to derive any of the equations (19)-(23).

\subsection{Results}

The counterfactual study aims at comparing the different outcomes generated for each economy by shocking, every time, a different sector. In this way, for each country one can establish in which sector a $10 \%$ increase in the state-of-the-art technology leads to the highest level of aggregate productivity.

According to the results shown in Table 7, aggregate productivity rises the most when the shock occurs in sectors featuring a large share $\alpha_{k}$ and a relatively low value of $\theta_{k}$, as those producing chemical products (CHEM) or food, beverages and tobacco (FOOD). ${ }^{33}$ In other words, for 17 out of the 19 economies of interest, the best equilibrium outcome in attained

\footnotetext{
${ }^{33}$ For Germany (DEU) and Japan (JPN), the algorithm employed to numerically solve the systems of equation does not return roots sufficiently close to zero; given the resulting value of the objective function, the corresponding aggregate productivity levels cannot be considered as reliable. In the case of UK (GBR), outcomes converge to the same value even though they refer to shocks in different sectors.
} 
when the shock in average efficiency occurs in sectors which absorb a large fraction of spending and, at the same time, display a high within-sector dispersion in industry efficiencies.

\section{Table 7: Results of the counterfactual simulation}

\begin{tabular}{|c|c|c|c|c|c|c|}
\hline \multirow[b]{3}{*}{ Country } & \multicolumn{3}{|c|}{ Heterogeneous trade elasticities } & \multicolumn{3}{|c|}{ Common trade elasticity } \\
\hline & \multicolumn{2}{|c|}{ Aggregate labor productivity } & \multirow[b]{2}{*}{$\begin{array}{c}\text { sector of } \\
\text { origin }\end{array}$} & \multicolumn{2}{|c|}{ Aggregate labor productivity } & \multirow[b]{2}{*}{$\begin{array}{c}\text { sector of } \\
\text { origin }\end{array}$} \\
\hline & before shock & $\begin{array}{c}\text { after shock } \\
\text { (highest value) }\end{array}$ & & before shock & $\begin{array}{c}\text { after shock } \\
\text { (highest value) }\end{array}$ & \\
\hline ARG & 0.294 & 0.4003 & NECL & 0.272 & 0.4652 & BMTL \\
\hline BRA & 0.139 & 0.2349 & CHEM & 0.146 & 0.5098 & CHEM \\
\hline CAN & 0.780 & 0.8857 & FOOD & 0.725 & 1.2893 & CHEM \\
\hline CZE & 0.152 & 0.1735 & FOOD & 0.192 & 0.2734 & FOOD \\
\hline DEU & 1.285 & 1.6883 & CHEM & 1.871 & n.a. & CHEM \\
\hline ESP & 0.446 & 0.5090 & FOOD & 0.459 & 0.8133 & CHEM \\
\hline FIN & 0.652 & 0.6941 & PLST & 0.499 & 0.9049 & PLST \\
\hline FRA & 0.885 & 1.0189 & FOOD & 0.964 & 1.6098 & CHEM \\
\hline GBR & 0.774 & 0.8261 & NECL & 0.845 & 1.1673 & - \\
\hline GRC & 0.345 & 0.3768 & FOOD & 0.313 & 0.5127 & CHEM \\
\hline ITA & 0.714 & 0.8708 & CHEM & 0.841 & 1.5585 & CHEM \\
\hline JPN & 1.185 & n.a & CHEM & 1.529 & n.a. & CHEM \\
\hline KOR & 0.401 & 0.6203 & FOOD & 0.460 & 0.9499 & CHEM \\
\hline MEX & 0.243 & 0.2712 & FOOD & 0.268 & 0.4959 & CHEM \\
\hline NOR & 0.954 & 1.0728 & FOOD & 0.891 & 1.3029 & CHEM \\
\hline POL & 0.111 & 0.1207 & CHEM & 0.108 & 0.1657 & CHEM \\
\hline PRT & 0.204 & 0.2251 & FOOD & 0.158 & 0.2767 & CHEM \\
\hline SWE & 0.796 & 0.8972 & FOOD & 0.745 & 1.1428 & FOOD \\
\hline TUR & 0.199 & 0.2212 & FOOD & 0.175 & 0.2849 & BMTL \\
\hline
\end{tabular}

Results are qualitatively similar when assuming common trade elasticity across manufacturing sectors. Nonetheless, by imposing the same $\theta$ parameter and using estimates from Appendix F, the most preferable outcome for each country turns out to be strongly biased in favor of the sector of chemical products (CHEM), which is the one with the largest share in total spending. Furthermore, both the pre- and post-shock levels of aggregate productivity appear as overrated.

It is important to stress that counterfactual outcomes shown in Table 7 can not be considered as a precisely quantification of the variation in aggregate productivities induced by technology shocks. As counterfactual values are generated by imposing trade balance, their comparison with the baseline values (computed by starting from available data, which reflect a world with large trade unbalances) would certainly represent a misleading exercise.

\section{Conclusion}

The paper develops a multi-sector extension of Eaton and Kortum (2002), in keeping with Costinot, Donaldson and Komunjer (2012) and, most of all, Shikher (2011). Manufacturing sectors, modelled as distinct continua of industries, are differentiated by their factor intensities and the within-sector elasticity of substitution among individual goods. Furthermore, in the 
probability distributions used to describe the heterogeneity in industry efficiencies within each sector, parameters are not restricted to be common across sectors, in contrast with most of the related literature.

The contribution of this paper is twofold. First, it provides a set of estimates of various trade elasticities at the sector level, for 13 different manufacturing sectors. By building on the insight of Caliendo and Parro (2012), it uses tariff data to model iceberg costs, in addition to distance and other gravity variables. GLS estimates, derived from an econometric approach that bears resemblance to a standard gravity estimation, reveal that sectors feature large differences in their trade elasticity to variable trade costs, mainly as a result of very different degrees of within-sector dispersion in industry efficiencies. Future research on the topic might investigate whether the dispersion at the sector level is somehow related to the specific within-sector elasticity of substitution among goods.

The second contribution of the paper concerns the implications of this cross-sector heterogeneity in trade elasticities. Accounting for this heterogeneity is important when inferring measures of relative productivity from data on trade and production, in order to carry out meaningful comparisons across both countries and sectors. The assumption of common trade elasticity, in fact, is shown to induce a large bias in these estimates, especially in some sectors. This bias comes up when measuring productivity either in terms of average efficiency (according to the original procedure outlined in this paper) or labor productivity. The paper shows how the latter measure is particularly useful to analyze the input reallocation processes induced by trade -within and between sectors- and their role in determining the benefits that each country obtains from opening to trade. Findings confirm that, even when using sectorlevel data, gains are mostly due to reallocations within, rather than between sectors, as shown in Pavcnik (2002) and other papers using firm-level data.

Finally, the cross-sector heterogeneity in trade elasticities matters when running general equilibrium counterfactual studies relevant for policy purposes. For instance, the paper provides counterfactual simulations that assess in which sector a positive, sector-specific shock to average productivity raises aggregate productivity the most at the country level. In so doing, it proves that outcomes are biased towards the sector with the largest share in total spending if trade elasticity is restricted to be common across all sectors.

In addition, the paper also contributes to the current debate about the effective size of the aggregate trade elasticity to trade costs in models with a unique continuum of all tradeable goods. It proves that welfare gains computed according to the well-established approach of Arkolakis, Costinot and Rodriguez-Clare (2012) are consistent with those computed in terms of labor productivity, using sectoral data and sector-specific elasticities, for particular values of the aggregate trade elasticity. These values are those found by Simonovska and Waugh (2011), which are lower than those suggested by previous literature. 


\section{Appendix}

\section{A Data source}

In the econometric application sketched in Section 3, the necessary condition for identifying $\theta_{k}$ is that tariffs are expressed as ad-valorem duty rates levied on the c.i.f. value of imported goods. When one takes this convention, a very simple specification arises: tariffs act multiplicatively with transport costs, rather than additively. This implies a couple of severe restrictions about data: $(i)$ bilateral trade-flows must be measured using import values instead of export values (since imports are conventionally measured according to their c.i.f. value) and (ii) tariff barriers must be available in form of ad-valorem tariffs.

Notwithstanding, the main problem with data is represented by the reconstruction of reliable market-shares. To compute the bilateral shares for any manufacturing sector, good quality data on sectoral import, export and production are required for a sufficiently large number of countries.

The main data source is the OECD STAN database, which reports information on gross output, value-added, import and export at current prices in national currencies, using ISIC Rev.3 as sectoral classification. Nevertheless, due to the re-export accounting problem, a careful treatment of these data is needed. To avoid discarding too many observations (those for which spending and/or home sales values appear unrealistic), the OECD STAN database has been integrated with the CEPII Trade, Production and Bilateral Protection Database, which collects information about industrial production and related variables from the same OECD STAN and from the UNIDO Industrial Statistics Database. ${ }^{34}$

This kind of data gives rise to a couple of problems. First, the CEPII database provides information in current US dollars at 3-digit level, but using ISIC Rev.2 instead of ISIC Rev.3. Secondly, a quality check of the OECD data reveals that, at 3-digit level, some measures ascribed to a given sector actually refer to aggregates made up of contiguous sectors. To overcome this problem, data from the two datasets have been reassembled into the 13 manufacturing sectors, listed in Table A.1, with a consequent reduction in the level of disaggregation. The resulting classification does not exactly match any of the official classifications used by the aforementioned institutions, even thought it is quite similar to the 2-digit ISIC Rev. 2. On the other hand, it roughly corresponds to the one used by Costinot et al. (2012). ${ }^{35}$ Both their classification and this one can be easily reconstructed starting from the 2-digit

\footnotetext{
${ }^{34}$ For each country-sector pair, values reported by OECD STAN have been discarded in favor of those reported by CEPII every time that volumes of export or import in STAN were disproportionately large relative to countries' gross output. In these cases, the observations reported by STAN might be influenced by the re-export/re-import accounting problem. The version of the CEPII database that has been used in this paper reports data for 67 developing and developed countries across 28 manufacturing sectors over the period 1980-2004. See Nicita and Olarreaga (2006) for a detailed description.

${ }^{35}$ The main difference is that, here, the sector of basic metals and that of fabricated metal products are considered separately. Costinot, Donaldson and Komunjer also include the FUEL sector (producing coke, refined petroleum products and nuclear fuels) that this paper has neglected, due to the lack of data. In the FUEL sector, tariff data are available only for a limited set of countries, mainly EU members. Since the latter do not apply any tariff on their bilateral trade flows, the resulting sample for this sector is excessively undersized, which makes the estimation of the trade structural equation impossible.
} 
ISIC Rev.3 and the 3-digit ISIC Rev 3.1 sector codes. The attribution of the latter to the broadly-defined sectors in Table A.1 is univocal and no conflict assignment arises.

Regarding bilateral trade flows, the main data source is the OECD STAN Bilateral Trade Database 2008. This database delivers information on the values of exports and imports (in US dollars, at current prices) by reporter, partner and economic activity, according to ISIC Rev.3. To match the restrictions imposed by the particular specification of the iceberg costs, trade volumes are measured with the c.i.f. import values reported by destination countries. Additional information is taken from CEPII, where trade data are obtained as mirror exports using WITS (World Bank's World Integrated Trade Solution) to get information from the COMTRADE database, provided by the United Nations.

\section{Table A.1: Definition of the sectoral classification and sector labels}

Correspondence with the 3 digit sector codes of ISIC Rev.2

\begin{tabular}{|c|c|c|}
\hline Sector label & ISIC rev.2 (3 digit) & Description \\
\hline \multirow{3}{*}{ FOOD } & $311-312$ & Food manufacturing \\
\hline & 313 & Beverage industries \\
\hline & 314 & Tobacco manufactures \\
\hline \multirow{4}{*}{ TXTL } & 321 & Manufacture of textiles \\
\hline & 322 & Manufacture of wearing apparel (except footwear) \\
\hline & 323 & $\begin{array}{l}\text { Manufacture of leather and products of leather, leather substitutes and fur (except } \\
\text { footwear, wearing apparel) }\end{array}$ \\
\hline & 324 & Manufacture of footwear \\
\hline \multirow{2}{*}{ WOOD } & 331 & Manufacture of wood and wood and cork products, except furniture \\
\hline & 332 & Manufacture of furniture and fixtures, except primarily of metal \\
\hline \multirow{2}{*}{ PAPR } & 341 & Manufacture of paper and paper products \\
\hline & 342 & Printing, publishing and allied industries \\
\hline \multirow{2}{*}{ CHEM } & 351 & Manufacture of industrial chemicals \\
\hline & 352 & Manufacture of other chemical products \\
\hline \multirow{2}{*}{ PLST } & 355 & Manufacture of rubber products \\
\hline & 356 & Manufacture of plastic products not elsewhere classified \\
\hline \multirow{3}{*}{ MNRL } & 361 & Manufacture of pottery, china and earthenware \\
\hline & 362 & Manufacture of glass and glass products \\
\hline & 369 & Manufacture of other non-metallic mineral products \\
\hline \multirow{2}{*}{ BMTL } & 371 & Iron and steel basic industries \\
\hline & 372 & Non-ferrous metal basic industries \\
\hline MTLP & 381 & Manufacture of fabricated metal products, except machinery and equipment \\
\hline MCHN & 382 & Manufacture of machinery except electrical \\
\hline \multirow[b]{2}{*}{ ELCT } & 383 & Manufacture of electrical machinery apparatus, appliances and supplies \\
\hline & 385 & $\begin{array}{l}\text { Manufacture of professional and scientific, of measuring and controlling equipment and of } \\
\text { photographic and optical goods }\end{array}$ \\
\hline TRSP & 384 & $\begin{array}{l}\text { Manufacture of transport equipment (ship building and repairing, railroad equipment, } \\
\text { motor veichles, motorbicycles and bicycles, aircrafts) }\end{array}$ \\
\hline NECL & 390 & $\begin{array}{l}\text { Other manufacturing industries (jewellery and related articles, musical instruments, } \\
\text { sporting and athletic goods, everything not else classified) }\end{array}$ \\
\hline
\end{tabular}

Tariffs, distance and other gravity variables are taken from the CEPII GeoDist Database. The latter provides an exhaustive set of gravity variables that Mayer and Zignago (2005) built on two different datasets. The first dataset, called geo_cepii, incorporates countryspecific variables for 225 countries, such as the geographical coordinates of their capital-city, 
the languages spoken in each country and a list of dummy variables that specifies, for instance, whether a country is landlocked or not or whether two trading partners have former colonial links. The second dataset, called dist_cepii, is dyadic: it includes only variables referred to pairs of countries, such as the distance between them (reported in kilometers). This variable, in particular, is measured by using city-level data to assess the geographic distribution of the population in each country. According to the procedure suggested by Head and Mayer (2002), the distance between two trading partners is calculated starting from the bilateral distances between some of the biggest cities in the two countries, weighted for the share that those cities represent in the overall population of the country pair.

\section{Table A.2: List of country labels (Section 3)}

\begin{tabular}{llll}
\hline \hline label country & label country & label country & label country \\
\hline ARG Argentina & DNK Denmark & ISR Israel & PRT Portugal \\
AUS Australia & ESP Spain & ITA Italy & ROM Romania \\
AUT Austria & JPT Estonia & KOR South Korea & RUS Russian Federation \\
BGR Bulgaria & FIN Finland & LTU Lithuania & SGP Singapore \\
BLX Belgium \& Luxembourg & FRA France & LVA Latvia & SVK Slovak Republic \\
BRA Brazil & GBR United Kingdom & MEX Mexico & SVN Slovenia \\
CAN Canada & GRC Greece & MLT Malta & SWE Sweden \\
CHE Switzerland & HKG Hong Kong & MYS Malaysia & THA Thailand \\
CHL Chile & HUN Hungary & NLD Netherlands & TUR Turkey \\
CHN China & IDN Indonesia & NOR Norway United States \\
CYP Cyprus & IND India & NZL New Zealand & VNM Vietnam \\
CZE Czech Republic & IRL Ireland & Poland South Africa \\
DEU Germany & ISL Iceland &
\end{tabular}

CEPII's data on common legal origin between trade partners are provided by Andrei Shleifer (http://post.economics.harvard.edu/faculty/shleifer/Data/qgov_web.xls).

Finally, more detailed information about tariff data is needed. The econometric application developed in Section 3 makes use of the tariff rates reported by the CEPII Bilateral Protection Database. These data are mainly taken from TRAINS, the TRade Analysis and INformation System developed by UNCTAD (United Nations Conference on Trade and Development). ${ }^{36}$ Hence, the primary data-source is the same used by Caliendo and Parro (2012), although they classify manufacturing sectors in a different way. CEPII reports tariffs as ad-valorem, even though they can take several forms in the real world. ${ }^{37}$ To overcome this problem, UNCTAD and World Bank jointly compute ad-valorem equivalents (AVEs) for tariffs that are not expressed as ad-valorem. The quality of these measures has been tested by Caliendo and Parro with encouraging results. ${ }^{38}$

\footnotetext{
${ }^{36}$ Their dataset, which covers the period 1989-2001,.provides several indicators on protection at country level. CEPII also uses information from Jon Haveman's treatment of TRAINS data (UTBC database) for the period 1989-2000. For the year 2001, CEPII employs the Dataset MAcMap (Market Access Map).

${ }^{37}$ In this respect, one can distinguish among specific tariffs (computed on physical quantities of imported goods), mixed tariffs (expressed as either specific or ad-valorem rates, generally depending on which tariff generates the largest revenue) or compound tariffs (including both ad-valorem and a specific component). In some cases, countries can also apply tariff-rate quotas, made up of a low tariff rate on an initial increment of imports -the "within-quota" quantity- and a very high tariff rate on imports which exceed that initial amount.

${ }^{38}$ When they compare specific tariffs with the AVEs for those observations for which both measures are available, they find no evidence of substantial differences. They also test the quality of the AVEs by running their estimations, based on observations for year 1993, using three different samples: a first time with a selected
} 
All data used in this paper refer to year 2000, since this year has the widest coverage in the dataset. The global sample is comprised of the 51 countries listed in Table A.2. When running the sector-by-sector estimation of trade elasticities, a different subsample has been used for each sector, depending on the number of countries for which a complete set of variables was actually available for that sector.

Regarding the empirical exercise performed in Section 4, the relative average efficiencies in any of the 13 manufacturing sectors were computed for a sample of the 20 countries listed in Table A.3. In order to exploit the data used in Section 3 on trade and production, these average efficiencies are computed in year 2000.

Data on manufacturing wages are taken from the U.S. Bureau of Labor Statistics; wage is measured as the total hourly compensation in manufacturing (in US dollars) from the Time Series Table of the International Comparisons Program of Hourly Compensation Costs in Manufacturing.

Sectoral value-added shares in total output, namely $\beta_{k}$, are computed on the basis of CEPII data on production and value added. Since the Cobb-Douglas parameters are the same all over the world, $\beta_{k}$ has been set at the level corresponding to the ratio between value-added and the value of gross production for an aggregate of OECD countries. The same value is then applied to the non-OECD members.

The assumption of homothetic preferences implies common shares $\alpha_{k}$ to all countries. Also in this case, the shares of expenditure computed for the aggregate of OECD members have been applied to any other country. The same criterion applies for the intermediate-input coefficients $\eta_{k h}$, obtained from the OECD Input-Output Tables. ${ }^{39}$ The latter are actually based on ISIC Revision 3, but working at 3-digit level it is quite easy to restore the 13 manufacturing sectors of Table A.1.

\section{Table A.3: List of country labels (Section 4)}

\begin{tabular}{llll}
\hline \hline label country & label country & label country & label country \\
\hline USA United States & DEU Germany & GRC Greece & NOR Norway \\
ARG Argentina & ESP Spain & ITA Italy & POL Poland \\
BRA Brazil & FIN Finland & JPN Japan & PRT Portugal \\
CAN Canada & FRA France & KOR South Korea & SWE Sweden \\
CZE Czech Republic & GBR United Kingdom & MEX Mexico & TUR Turkey \\
\hline \hline
\end{tabular}

\footnotetext{
sample of tariffs that are only reported as ad-valorem, then with the full sample including ad-valorem + AVEs and, finally, using the full sample with ad-valorem + specific tariffs. Their results are robust to all the three different formulations.

${ }^{39}$ These tables report the value of intermediate inputs in row $h$ required to produce one dollar of the final output in column $k$. As stressed by Di Giovanni and Levchenko (2010), at such level of aggregation, inputoutput matrices look very similar across OECD countries.
} 


\section{B Prices under perfect competition}

This appendix proves that, when efficiencies are Fréchet-distributed, the implied distribution of unit costs of production translates into a Weibull distribution of prices.

In order to prove that,one has to introduce specific assumptions on market structure and preferences. Under perfect competition and CRTS, the analysis largely simplifies: marginal costs become constant and all producers price at marginal cost. As long as goods are priced, conditional on source and destination, according to equation (5), the c.d.f. of the prices of goods produced in country $i$ and sector $k$ and shipped to $n$ turns out to be:

$$
\begin{aligned}
& G_{n i, k}(p)=\operatorname{Pr}\left[p_{n i, k} \leq p\right]=\operatorname{Pr}\left[\frac{c_{i, k} d_{n i, k}}{z_{i, k}} \leq p\right]=1-\operatorname{Pr}\left[z_{i, k} \leq \frac{c_{i, k} d_{n i, k}}{p}\right]= \\
& =1-F_{i, k}\left(\frac{c_{i, k} d_{n i, k}}{p}\right)=1-\exp \left\{-T_{i, k}\left(\frac{c_{i, k} d_{n i, k}}{p}\right)^{-\theta_{k}}\right\}=1-\exp \left\{-T_{i, k}\left(c_{i, k} d_{n i, k}\right)^{-\theta_{k}} p^{\theta_{k}}\right\} .
\end{aligned}
$$

Within each country, any good is provided only by the cheapest supplier. Thus, in each country the price level only depends on prices charged by the lowest seller for each good (prices potentially set by its competitors are irrelevant at all). Starting from the above expression and removing the condition on country $i$ to be the source, the price distributions in sector $k$ at location $n$ is proved to be:

$$
\begin{aligned}
& G_{n, k}(p)=\operatorname{Pr}\left[P_{n, k}<p\right]=\operatorname{Pr}\left[\min p_{n i, k}<p\right]=1-\operatorname{Pr}\left[\min p_{n i, k} \geq p\right]= \\
& =1-\operatorname{Pr}\left[p_{n 1, k} \geq p, \ldots, p_{n N, k} \geq p\right]=1-\operatorname{Pr}\left[p_{n 1, k} \geq p\right] \ldots \operatorname{Pr}\left[p_{n N, k} \geq p\right]= \\
& =1-\left(1-\operatorname{Pr}\left[p_{n 1, k}<p\right]\right) \ldots\left(1-\operatorname{Pr}\left[p_{n N, k}<p\right]\right) . \\
& \text { Hence: } G_{n, k}(p)=1-\prod_{i=1}^{N}\left[1-G_{n i, k}(p)\right]=1-\prod_{i=1}^{N}\left[\exp \left\{-T_{i, k}\left(c_{i, k} d_{n i, k}\right)^{-\theta_{k}} p^{\theta_{k}}\right\}\right]= \\
& =1-\exp \sum_{i=1}^{N}\left\{-T_{i, k}\left(c_{i, k} d_{n i, k}\right)^{-\theta_{k}} p^{\theta_{k}}\right\}=1-\exp \left\{-p^{\theta_{k}} \sum_{i=1}^{N} T_{i, k}\left(c_{i, k} d_{n i, k}\right)^{-\theta_{k}}\right\}= \\
& =1-\exp \left\{-\Phi_{n, k} p^{\theta_{k}}\right\}, \text { where } \Phi_{n, k}=\sum_{i=1}^{N} T_{i, k}\left(c_{i, k} d_{n i, k}\right)^{-\theta_{k}} .
\end{aligned}
$$

The derivative of $G_{n, k}(p)$ is: $\frac{\partial G_{n, k}(p)}{\partial p}=\theta_{k} \Phi_{n, k} p^{\theta_{k}-1} \exp \left\{-\Phi_{n, k} p^{\theta_{k}}\right\}$.

This result shows that prices follow a Weibull distribution within each sector. Indeed, a random variable $X$ is Weibull-distributed with parameters $a$ and $b$ when its density function, namely $f(x)$, is:

$$
f(x)=\frac{b}{a}\left(\frac{x}{a}\right)^{b-1} \exp \left\{-(x / a)^{b}\right\} .
$$

By setting $b=\theta_{k}$ and $\Phi_{n, k}=(1 / a)^{b}$ (which implies $a=\Phi_{n, k}^{-1 / \theta_{k}}$ ), it follows that: $p \sim W \operatorname{eibull}\left(\Phi_{n, k}^{-1 / \theta_{k}}, \theta_{k}\right)$.

Exploiting the properties of Weibull distributions, it is quite easy to derive the exact price-index for each country-sector pair. Provided that $X \sim \operatorname{Weibull}(a, b)$, the moment of 
order $t$ of its distribution is: $m_{t}=\alpha^{t} \Gamma\left(1+\frac{t}{\beta}\right)$. Therefore, the moment of order $\left(1-\sigma_{k}\right)$ of the price distribution is simply:

$$
E\left[\left(p_{n, k}\right)^{1-\sigma_{k}}\right]=\Phi_{n, k}^{-\left(1-\sigma_{k}\right) / \theta_{k}} \Gamma\left(1+\frac{1-\sigma_{k}}{\theta_{k}}\right) .
$$

Under CES preferences in consumption, equation (4) can be finally proved:

$$
\begin{aligned}
& p_{n, k}=\left[\int p_{n, k}^{1-\sigma_{k}}(j) d G_{n, k}(p)\right]^{\frac{1}{1-\sigma_{k}}}=\left(E\left[p_{n, k}^{1-\sigma_{k}}\right]\right)^{\frac{1}{1-\sigma_{k}}}=\left[\Phi_{n, k}^{-\frac{1-\sigma_{k}}{\theta_{k}}} \Gamma\left(1+\frac{1-\sigma_{k}}{\theta_{k}}\right)\right]^{\frac{1}{1-\sigma_{k}}}= \\
& =\Phi_{n, k}^{-1 / \theta_{k}}\left[\Gamma\left(\frac{\theta_{k}+1-\sigma_{k}}{\theta_{k}}\right)\right]^{\frac{1}{1-\sigma_{k}}}=\gamma_{k} \Phi_{n, k}^{-1 / \theta_{k}}, \text { where } \gamma_{k}=\left[\Gamma\left(\frac{\theta_{k}+1-\sigma_{k}}{\theta_{k}}\right)\right]^{\frac{1}{1-\sigma_{k}}} .
\end{aligned}
$$

\section{Prices under Bertrand competition}

Under perfect competition, in the EK model prices vary inversely with efficiency, in such a way as to eliminate any variation in productivity, as measured by the value of output per unit input. Hence, measured productivity turns out to be equal for all producers, regardless of what they produce and, most importantly, of their own level of efficiency. ${ }^{40}$ The same occurs in a multi-sector extension of EK: all producers using the same input bundle (with unit cost $c_{i k}$ ) feature the same ratio between the values of output and input. To more carefully assess the relationship between efficiency and productivity (and size and exporting), Bernard et al. (2003, BEJK hereinafter) propose a variant of EK built on the assumption of Bertrand competition.

This assumption can be obviously applied even in a multi-sector framework. Let the state of the art technology for each good be proprietary. As with perfect competition, only the most efficient technology is used for making each good. The main difference is that now the price is above cost: the lowest-cost producer charges the highest price that keeps the competition at bay. On one hand, this firm is constrained not to charge more than the second-lowest cost of supplying the market; in the open economy, the latter is given by:

$$
\varsigma_{i, k}^{(2)}(j)=\min \left\{\varsigma_{i i, k}^{(2)}(j), \min _{n \neq i}\left\{\varsigma_{i n, k}^{(1)}(j)\right\}\right\},
$$

where $\varsigma_{i n, k}^{(1)}(j)$ is the lowest cost at which a foreign competitor from country $n$ can supply $j$ to market $i{ }^{41}$ In each market, the second best supplier can be either the second-cheapest domestic producer or the lowest cost supplier among foreign competitors.

\footnotetext{
${ }^{40}$ In the EK model with a unique continuum of tradable goods, an industry with efficiency $z_{i}(j)$ produces, per unit of input, an output with value $p_{i}(j) z_{i}(j)$. Provided that this industry is actually the cheapest source for good $j$ in its domestic market, the price charged under perfect competition coincides with the unit cost of production: $p_{i}(j)=c_{i} / z_{i}(j)$. The observed productivity is then $c_{i}$ for all industries $j$ in country $i$, the unit cost of an input bundle being the same for any producer at that location.

${ }^{41}$ Provided that $\varsigma_{i, k}^{(s)}$ is the $s^{\prime}$ th lowest cost (inclusive of iceberg costs) of supplying one unit of $j$ to market $i$, all potential suppliers of the good in the country of interest can be ranked starting from the one featuring the lowest $\operatorname{costs} \varsigma_{i, k}^{(1)}$, onwards.
} 
On the other hand, as in monopolistic competition model as Dixit-Stiglitz (1977), firms servicing any market can charge a markup not higher than: $\bar{m}_{k}=\sigma_{k} /\left(\sigma_{k}-1\right)$, provided that $\sigma_{k}>1$. It follows that the price actually paid by consumers in country $i$ is:

$$
p_{i, k}(j)=\min \left\{\bar{m}_{k} \varsigma_{i, k}^{(1)}(j), \varsigma_{i, k}^{(2)}(j)\right\},
$$

which means that, in any market, the lowest-cost supplier charges a price equal to the minimum between Dixit-Stiglitz markup over cost, and the unit cost of the second lowest cost supplier.

To prove that, under this market regime, equation (6) still holds, this Appendix re-runs the same steps followed by BEJK in their online appendix, in which they derive the results for a model with an unique, undifferentiated continuum of goods.

Among the different layers of efficiency (and costs) for producing some good in sector $k$ and country $i$, the only relevant for the analysis are then the highest and second highest efficiencies, denoted as $z_{i, k}^{(1)}$ and $z_{i, k}^{(2)}$, respectively. Their joint (Fréchet) distribution is:

$$
\begin{aligned}
& F_{i, k}\left(z_{1}, z_{2}\right)=\operatorname{Pr}\left[Z_{i, k}^{(1)} \leq z_{1}, Z_{i, k}^{(2)} \leq z_{2}\right]= \\
& =\left[1+T_{i, k}\left(z_{2}^{-\theta_{k}}-z_{1}^{-\theta_{k}}\right)\right] \exp \left\{-T_{i, k} z_{2}^{-\theta_{k}}\right\} \text { for } 0 \leq z_{2} \leq z_{1},
\end{aligned}
$$

which can be translated into a distribution $G_{n i, k}(\varsigma)$ of the lowest and second lowest cost at which country $i$ can deliver a good produced in sector $k$ to country $n$. As suggested by BEJK in their online appendix, one can use the complementary distribution $G_{n i, k}^{c}$ :

$$
\begin{aligned}
& G_{n i, k}^{c}\left(\varsigma_{1}, \varsigma_{2}\right)=\operatorname{Pr}\left[\varsigma_{i, k}^{(1)} \geq \varsigma_{1}, \varsigma_{i, k}^{(2)} \geq \varsigma_{2}\right]= \\
& =\operatorname{Pr}\left[Z_{i, k}^{(1)} \leq \frac{c_{i, k} d_{n i, k}}{\varsigma_{1}}, Z_{i, k}^{(2)} \leq \frac{c_{i, k} d_{n i, k}}{\varsigma_{2}}\right]=F_{i, k}\left(\frac{c_{, i k} d_{n i, k}}{\varsigma_{1}}, \frac{c_{i, k} d_{n i, k}}{\varsigma_{2}}\right),
\end{aligned}
$$

provided that $\varsigma_{1} \leq \varsigma_{2}$. The above result implies that: $G_{n i, k}\left(\varsigma_{1}, \varsigma_{2}\right)=1-F_{i, k}\left(\frac{1}{\varsigma_{1}}, \frac{1}{\varsigma_{2}}\right)$, where the parameter $T_{i, k}\left(c_{i, k} d_{n i, k}\right)^{-\theta_{k}}$ regulates the location of the joint distribution $F_{i, k} \cdot{ }^{42}$

The distribution $G_{n, k}$ of the two lowest costs of delivering goods $k$ to market $n$ (regardless their source) is then: $G_{n, k}\left(\varsigma_{1}, \varsigma_{2}\right)=1-G_{n, k}^{c}\left(0, \varsigma_{2}\right)-G_{n, k}^{c}\left(\varsigma_{1}, \varsigma_{1}\right)+G_{n, k}^{c}\left(\varsigma_{1}, \varsigma_{2}\right)$.

The complementary distribution of $G_{n, k}$, namely $G_{n, k}^{c}$, is then:

$$
\begin{aligned}
& G_{n, k}^{c}\left(\varsigma_{1}, \varsigma_{2}\right)=\prod_{i=1}^{N} G_{n i, k}^{c}\left(\varsigma_{2}, \varsigma_{2}\right)+\sum_{i=1}^{N}\left[G_{n i, k}^{c}\left(\varsigma_{1}, \varsigma_{2}\right)-G_{n i, k}^{c}\left(\varsigma_{2}, \varsigma_{2}\right)\right] \prod_{m \neq 1}^{N} G_{n m, k}^{c}\left(\varsigma_{1}, \varsigma_{2}\right)= \\
& =\sum_{i=1}^{N}\left[\frac{T_{i, k}}{\left(c_{i, k} d_{n i, k}\right)^{\theta_{k}}}\left(\varsigma_{2}^{\theta_{k}}-\varsigma_{1}^{\theta_{k}}\right) \exp \left\{\frac{-T_{i, k}}{\left(c_{i, k} d_{n i, k}\right)^{\theta_{k}}} \varsigma_{2}^{\theta_{k}}\right\}\right] \prod_{m \neq 1}^{N} \exp \left\{\frac{-T_{m, k}}{\left(c_{m, k} d_{n m, k}\right)^{\theta_{k}}} \varsigma_{2}^{\theta_{k}}\right\}+ \\
& +\prod_{i=1}^{N} \exp \left\{\frac{-T_{i, k}}{\left(c_{i, k} d_{n i, k}\right)^{\theta_{k}}} \varsigma_{2}^{\theta_{k}}\right\}=e^{-\Phi_{n, k} \varsigma_{2}^{\theta_{k}}}+\left(\varsigma_{2}^{\theta_{k}}-\varsigma_{1}^{\theta_{k}}\right) e^{-\Phi_{n, k} \varsigma_{2}^{\theta_{k}}} \sum_{i=1}^{N} \frac{T_{i, k}}{\left(c_{i, k} d_{n i, k}\right)^{\theta_{k}}} .
\end{aligned}
$$

\footnotetext{
${ }^{42}$ When a random variable $Z$ is Fréchet distributed, also the variable $\lambda Z$ is Fréchet, provided that $\lambda$ is a positive constant. This property holds for the analogue to the Fréchet for the joint distributions of the order statistics $Z^{(1)}$ and $Z^{(2)}$.
} 
The last expression corresponds to the c.d.f. of a distribution $F_{n, k}\left(\frac{1}{\varsigma_{1}}, \frac{1}{\varsigma_{2}}\right)$ with parameters $\theta_{k}$ and $\Phi_{n, k}$, the latter being the same delivered by equation (3). Plugging $G_{n, k}^{c}$ into the expression for $G_{n, k}$, it can be proved that the joint distribution of the costs of supplying some good to country $n$ for the actual seller and its closest competitors (either domestic or foreign) is: $G_{n, k}=1-\exp \left\{-\Phi_{n, k} \varsigma_{1}^{\theta_{k}}\right\}-\Phi_{n, k} \varsigma_{1}^{\theta_{k}} \exp \left\{-\Phi_{n, k} \varsigma_{2}^{\theta_{k}}\right\}$.

When $\varsigma_{2}$ goes to infinity in the above c.d.f., the marginal distribution of the lowest costs in sector $k$ and country $n$ becomes a Weibull:

$$
G_{n, k}^{(1)}\left(\varsigma_{1}\right)=\operatorname{Pr}\left[\varsigma_{i, k}^{(1)} \leq \varsigma_{1}\right]=1-\exp \left\{-\Phi_{n, k} \varsigma_{1}^{\theta_{k}}\right\} .
$$

Notice that, if country $i$ were the only supplier in sector $k$, the distribution of the lowest cost in $n$ would be: $G_{n i, k}^{(1)}(\varsigma)=1-\exp \left\{-T_{i, k}\left(c_{i, k} d_{n i, k}\right)^{-\theta_{k}} \varsigma^{\theta_{k}}\right\}$. Then, the probability that country $i$ sells some good from sector $k$ in market $n$ is: ${ }^{43}$

$$
\pi_{n i, k}=\int_{0}^{\infty} \prod_{m \neq 1}^{N}\left[1-G_{n m, k}^{(1)}(\varsigma)\right] d G_{n i, k}^{(1)}(\varsigma)=\frac{T_{i, k}\left(c_{i, k} d_{n i, k}\right)^{-\theta_{k}}}{\Phi_{n, k}}
$$

To move from the cost distribution to the distribution of prices, it is necessary to consider how markups are distributed within the sector of interest. Since consumers can shift their demand away from any $j$, exploiting the substitutability across similar products from the same product category, the markup charged by sellers in market $n$ is bounded by $M_{n, k}=\min \left\{M_{n, k}^{\prime}, \bar{m}_{k}\right\}$, where $\bar{m}_{k}=\sigma_{k} /\left(\sigma_{k}-1\right)$ while $M_{n, k}^{\prime}=\varsigma_{n, k}^{(1)} / \varsigma_{n, k}^{(2)}$ measures the gap in the unit cost between the best and second best producer. To prove that sectoral markups are Pareto-distributed (truncated at $\bar{m}_{k}$ ), it is sufficient to prove that their distribution, conditional on $\varsigma_{n, k}^{(2)}=\varsigma_{2}$, is Pareto and does not depend on $\varsigma_{2}$. Indeed, it holds that:

$$
\begin{aligned}
& \operatorname{Pr}\left[M_{n, k}^{\prime} \leq m^{\prime} \mid \varsigma_{n, k}^{(2)}=\varsigma_{2}\right]=\operatorname{Pr}\left[\varsigma_{2} / m^{\prime} \leq \varsigma_{n, k}^{(1)} \leq \varsigma_{2} \mid \varsigma_{n, k}^{(2)}=\varsigma_{2}\right]= \\
& =\frac{\int_{\varsigma_{2} / m^{\prime}}^{\varsigma_{2}} g_{n, k}\left(\varsigma_{1}, \varsigma_{2}\right) d \varsigma_{1}}{\int_{0}^{\zeta_{2}^{2}} g_{n, k}\left(\varsigma_{1}, \varsigma_{2}\right) d \varsigma_{1}}=\frac{\varsigma_{2}^{\theta_{k}}-\left(\varsigma_{2} / m^{\prime}\right)^{\theta_{k}}}{\varsigma_{2}^{\theta_{k}}}=1-\left(m^{\prime}\right)^{\theta} \quad \forall m^{\prime} \geq 1,
\end{aligned}
$$

where $g_{n, k}\left(\varsigma_{1}, \varsigma_{2}\right)$ is the joint density function corresponding to $G_{n, k}\left(\varsigma_{1}, \varsigma_{2}\right)$.

Since $p_{n, k}(j)=\min \left\{\bar{m}_{k} \varsigma_{n, k}^{(1)}(j), \varsigma_{n, k}^{(2)}(j)\right\}$ and both the distributions of unit costs and markups are known, the distribution of prices can be finally derived. In particular, by imposing the usual EK restriction on parameter (i.e. $\sigma_{k}<1+\theta_{k}$ ), the moment of order $\left(1-\sigma_{k}\right)$ of the price distribution turns out to be:

$$
\begin{aligned}
& E\left[P_{n, k}^{1-\sigma_{k}}\right]=\int_{1}^{\infty} E\left[P_{n, k}^{1-\sigma_{k}} \mid M_{n, k}^{\prime}=m^{\prime}\right] \theta_{k}\left(m^{\prime}\right)^{-\left(1+\theta_{k}\right)} d m^{\prime}= \\
& =\int_{1}^{\bar{m}_{k}} E\left[\left(\varsigma_{n, k}^{(2)}\right)^{1-\sigma_{k}}\right] \theta_{k}\left(m^{\prime}\right)^{-\left(1+\theta_{k}\right)} d m^{\prime}+\int_{\bar{m}_{k}}^{\infty} E\left[\left(\frac{\bar{m}_{k} \varsigma_{n, k}^{(2)}}{m^{\prime}}\right)^{1-\sigma_{k}}\right] \theta_{k}\left(m^{\prime}\right)^{-\left(1+\theta_{k}\right)} d m^{\prime}=
\end{aligned}
$$

\footnotetext{
${ }^{43}$ As claimed by BEJK, the probability $\pi_{n i, k}$ can be calculated by integrating over all the ways that country $i$ can undercut the competition from all other countries. In the setting outlined in the Appendix, among all sources other than $i$, the probability that the lowest cost of supplying country $n$ exceed $\varsigma$ is: $\prod_{m \neq 1}^{N}\left[1-G_{n m, k}^{(1)}(\varsigma)\right]$.
} 


$$
=E\left[\left(\varsigma_{n, k}^{(2)}\right)^{1-\sigma_{k}}\right]\left(\left(1-\bar{m}_{k}^{-\theta_{k}}\right)+\bar{m}_{k}^{-\theta_{k}} \frac{\theta_{k}}{1+\theta_{k}-\sigma_{k}}\right),
$$

where $P_{n, k}$ is the random variable that describes price distribution in sector $k$ and country $n$. Using the density function for distribution $G_{n, k}^{(2)}$, namely $g_{n, k}^{(2)}\left(\varsigma_{2}\right)$, one can prove that:

$$
\begin{aligned}
& E\left[\left(\varsigma_{n, k}^{(2)}\right)^{1-\sigma_{k}}\right]=\int_{0}^{\infty} \varsigma_{2}^{1-\sigma_{k}} g_{n, k}^{(2)}\left(\varsigma_{2}\right) d \varsigma_{2}= \\
& =\Phi_{n, k}^{\frac{\sigma_{k}-1}{\theta_{k}}} \int_{0}^{\infty} \varphi^{\frac{1-\sigma_{k}+\theta_{k}}{\theta_{k}}} \exp \{-\varphi\} d \varphi=\Phi_{n, k}^{\frac{\sigma_{k}-1}{\theta_{k}}} \Gamma\left(\frac{1+2 \theta_{k}-\sigma_{k}}{\theta_{k}}\right) .
\end{aligned}
$$

By combining these results, the exact price index in country $i$ and sector $k$ turns out to be:

$$
p_{i, k}=\gamma_{k}^{\prime} \Phi_{i, k}^{-1 / \theta_{k}} \text { where } \gamma_{k}^{\prime} \equiv\left[\frac{1+\theta_{k}-\sigma_{k}+\left(\sigma_{k}-1\right) \bar{m}_{k}^{-\theta_{k}}}{1+\theta_{k}-\sigma_{k}} \Gamma\left(\frac{1+2 \theta_{k}-\sigma_{k}}{\theta_{k}}\right)\right]^{\frac{1}{1-\sigma_{k}}} .
$$

As in the BEJK model with only one sector, the probability for country $n$ to export to market $i$ in any sector $k$ is given by $n$ 's contribution to the price parameter $\Phi_{i, k}$. This probability $\pi_{i n, k}$ corresponds to the market-share $X_{i n, k} / X_{i, k}$, which means that equation (6) also holds under Bertrand competition.

The results shown in this Appendix deliver two fundamental key-points. First, the main results of the BEJK model apply within each sector in a generalized version of the model, featuring different product categories. Secondly, these results are qualitatively the same of those derived under perfect competition. Even when considering their multi-sector extensions, BEJK and EK share some of their structural relationships, in particular those providing a link between models and bilateral trade data. Therefore, the findings of the econometric study developed in this paper can apply indifferently to multi-sector extensions of both models, as they are robust to the assumption of perfect, rather than Bertrand competition.

\section{Trade Structural Equations}

This Appendix reports the analytical steps which deliver equation (8). The starting point is represented by equation (7). When evaluated at $n=i,(7)$ shows that sectoral priceindices are decreasing in the market-share of local producers: lower trade openness implies lower inflows of cheaper goods produced (more efficiently) abroad. Dividing the resulting expression for $p_{i, k}$ by its analogous for country $n$, relative prices turn out to be:

$$
\frac{p_{i, k}}{p_{n, k}}=\left(\frac{T_{i, k}}{T_{n, k}}\right)^{-1 / \theta_{k}}\left(\frac{w_{i}}{w_{n}}\right)^{\beta_{k}}\left(\frac{\rho_{i, k}}{\rho_{n, k}}\right)^{1-\beta_{k}}\left(\frac{X_{i i, k} / X_{i, k}}{X_{n n, k} / X_{n, k}}\right)^{1 / \theta_{k}} .
$$


The above expression can be plugged into equation (7), normalized by importer's home sales delivers, namely:

$$
\frac{X_{n i, k}}{X_{n n, k}}=\frac{T_{i, k}\left(c_{i, k} d_{n i, k}\right)^{-\theta_{k}}}{T_{n, k} c_{n, k}^{-\theta_{k}}}=\frac{T_{i, k}}{T_{n, k}} d_{n i, k}^{-\theta_{k}}\left(\frac{w_{i}}{w_{n}}\right)^{-\beta_{k} \theta_{k}}\left(\frac{\rho_{i, k}}{\rho_{n, k}}\right)^{-\left(1-\beta_{k}\right) \theta_{k}} .
$$

By so doing, one can retrieve a sort of "normalized" trade-share equation:

$$
\frac{X_{n i, k}}{X_{n n, k}}=\frac{X_{i i, k} / X_{i, k}}{X_{n n, k} / X_{n, k}}\left(\frac{p_{i, k}}{p_{n, k}}\right)^{-\theta_{k}} d_{n i, k}^{-\theta_{k}} .
$$

As mentioned in Sections 3 and 4, a key property of the models built on EK is that, within each country, the price of the goods imported from any trade partner features the same distribution of the price of the goods produced domestically. Thus, the price index in country $i$ and sector $k$ can be computed by combining (with a CES aggregator) the prices delivered by equation (5) when evaluated for $n=i$, that is, when goods $j$ are supplied by domestic industries. Plugging the resulting price-index, namely $p_{i, k}=\gamma_{k} w_{i}^{\beta_{k}} \rho_{i, k}^{1-\beta_{k}} T_{i, k}^{-1 / \theta_{k}}$, into the above "normalized" trade-share equation, it is possible to derive the structural equation (8), which describes bilateral trade at sector level.

\section{E Labor productivity indices}

In the model outlined in this paper, labor is the only primary input. At any level (industry, sector or whole manufactures) value-added is given by the difference between the value of output and the value of intermediate inputs. Starting from this identity, one can derive an aggregate production function, in which output is linear in the total amount of labor employed in its production.

Consider sector $k$ in country $i$. Solving the firm's cost minimization problem, for any industry $j$ in sector $k$ the demand of intermediates coming from sector $h$ turns out to be:

$$
M_{i, k h}(j)=\frac{w_{i}}{p_{i, h}} \eta_{k h} \frac{1-\beta_{k}}{\beta_{k}} L_{i, k}(j) .
$$

By integrating over the continuum of industries, it can be proved that sector $k$ 's overall requirement of inputs from sector $h$ is: $M_{i, k h}=\frac{1-\beta_{k}}{\beta_{k}} \eta_{k h}\left(w_{i} / p_{i, h}\right) L_{i, k}$. This implies that:

$$
\begin{aligned}
p_{i, k} Q_{i, k} & =w_{i} L_{i, k}+\sum_{h=1}^{K} p_{i, h} M_{i, k h}=w_{i} L_{i, k}+\sum_{h=1}^{K} p_{i, h}\left(\frac{w_{i}}{p_{i h}} \eta_{k h} \frac{1-\beta_{k}}{\beta_{k}} L_{i, k}\right)= \\
& =w_{i} L_{i, k}+w_{i} L_{i, k} \frac{1-\beta_{k}}{\beta_{k}} \underbrace{\sum_{h=1}^{K} \eta_{k h}}_{=1}=w_{i} L_{i, k}\left(1+\frac{1-\beta_{k}}{\beta_{k}}\right)=\frac{w_{i}}{\beta_{k}} L_{i, k} .
\end{aligned}
$$

The production function, at sector level, is then: $Q_{i, k}=A_{i, k} L_{i, k}$, where $A_{i, k} \equiv \frac{1}{\beta_{k}}\left(w_{i} / p_{i, k}\right)$ is the aggregate labor productivity in sector $k$. The total manufacturing production can be 
obtained by using a Cobb-Douglas aggregator of the amounts of goods produced in each sector, in a way consistent with the assumptions on preferences. Hence, equation (17) is finally proved:

$$
\begin{aligned}
Q_{i} & =\prod_{k=1}^{K} Q_{i k}^{\alpha_{k}}=\prod_{k=1}^{K}\left(A_{i k} L_{i k}\right)^{\alpha_{k}}=L_{i} \prod_{k=1}^{K}\left(A_{i k} \frac{L_{i k}}{L_{i}}\right)^{\alpha_{k}} \\
& \Rightarrow Q_{i}=A_{i} L_{i} \quad \text { where } \quad A_{i}=\prod_{k=1}^{K}\left(s_{i k} A_{i k}\right)^{\alpha_{k}} .
\end{aligned}
$$

\section{F Pooled Regression}

An interesting exercise is that of running a pooled regression, where equation (12) is slightly modified in such a way as to deliver a unique value for $\theta$. Consider a model where all tradable goods belong the same continuum; a unique value for the elasticity of substitution, namely $\sigma$, applies universally. Everything looks like as in the standard version of EK: industry efficiencies are independently drawn from a country-specific distribution $Z_{i}$, which is Fréchet with parameters $T_{i}$ and $\theta$.

Albeit the procedure outlined in Section 3 is not specifically derived to estimate $\theta$ at aggregate level, it can be slightly modified in order to allow for a rough estimation of this parameter, based on sectoral data. The simplifying assumption is that, for each country pair, iceberg costs only differ across sectors in their tariff component. In formal terms, equation (10) can be modified as follows: $\ln d_{i n, k}=\ln \tau_{i n, k}+\ln \delta_{i n}$, where the non-tariff component, namely $\delta$, is restricted to be sector-invariant. ${ }^{44}$

An estimate of the value of the $\theta$ parameter for the whole manufactures can thus be obtained by regressing a modified version of equation (12) over the different sectors. Equation (12) becomes:

$$
\begin{aligned}
\ln X_{n i, k}^{\prime} / X_{n n, k}^{\prime}= & -\theta \ln \tau_{i n, k}-\theta \rho \ln \left(d i s t_{n i}\right)-\theta\left[\xi_{1} b_{n i}-\xi_{2} l_{n i}+\right. \\
& \left.-\xi_{3} c_{n i}-\xi_{4} h_{n i}\right]+S_{i}-S_{n}-\theta \nu_{n i, k}
\end{aligned}
$$

where all parameters $\theta, \rho$ and $\left\{\xi_{s}\right\}_{s=1}^{4}$ are no longer indexed by $k$. In the above equation, $S_{i} \equiv \ln T_{i}-\beta \theta \ln w_{i}-(1-\beta) \theta \ln p_{i}$, while $\beta$ is the aggregate labor share in manufacturing and $p_{i}$ is the exact price-index for all manufacturing goods. ${ }^{45}$

\footnotetext{
${ }^{44}$ In adapting the econometric model for the estimation of a unique $\theta$, it could appear more suitable the imposition of a unique tariff rate $\tau_{i n}$, which universally applies to all commodities traded from $n$ to $i$. Nevertheless, as a general statement, the higher is the level of aggregation over product categories, the poorer is the quality of tariff data. Therefore, it makes little sense to reconstruct a unique value for tariff barriers between two countries, which applies without differentiation by product category. This exercise would entails averaging tariff rates across completely different categories of commodities and according to arbitrary weights, or weights that could give rise to severe endogeneity problems. For these reason, the econometric exercise run in this Appendix keeps using sector-specific values of tariff rates.

${ }^{45}$ In this one-sector framework, the bundle of intermediate goods is the same for all industries within the same country; thus, the corresponding price-index coincides with the consumer price-index of tradeable goods.
} 
A very careful treatment of the error term $\nu$ is needed. In this econometric application, $\nu$ is expected to be correlated across observations which refer to the same country pair. In other words, in addition to the two-way and one-way components discussed in Section 3.3, one needs to account for a third, sector-specific component. This additional term makes the estimation of the variance-covariance matrix (needed to correct for heteroskedasticity) very cumbersome. The main diagonal of this matrix is now represented by the empirical counterpart of $E\left(\nu_{n i, k} \nu_{n i, k}\right)$, which reflects the interaction among all three components of the error term. Out of the main diagonal, in addition to many zeros, it is possible to distinguish three different families of non-zero elements:

$i)$ the estimate of covariance $E\left(\nu_{n i, k} \nu_{n i, h}\right)$, induced by the combination between the one-way and the two-way component (which affects bilateral trade when it occurs in different sectors but same direction)

ii) the estimate of covariance $E\left(\nu_{n i, k} \nu_{i n, k}\right)$, arising from the combination of the sectorspecific and the two-way component (which affects bilateral trade in the same sector, but opposite direction)

iii) the estimate of covariance $E\left(\nu_{n i, k} \nu_{i n, h}\right)$, originated by the sole two-way component (which affect bilateral trade that occurs in different sectors and direction).

By imposing this structure on the variance-covariance matrix, one can obtain the GLS estimates reported in Table F.1. Since this exercise aims at retrieving a measure of the aggregate trade elasticity in manufactures, the only estimated coefficient of interest, here, is that on tariffs: even in this case, the opposite in sign of the estimated value of this coefficient provides a direct measure of the $\theta$ parameter. The estimate is 2.63 , a very low value compared to previous estimates in literature. Nevertheless, estimations performed over time (following widely different approaches) have always and systematically obtained lower values for $\theta$, with respect to the original 8.28 estimated by EK. In fact, Alvarez and Lucas (2007) calibrated a value of 6.67; then, Simonovska and Waugh (2011) identified a range from 2.47 to 4.42, being 4 their preferred values.

Table F.1: Results from pooled regression, GLS

\begin{tabular}{lccccc}
\hline \hline & $\begin{array}{c}\text { value of } \\
\text { estimated } \\
\text { coeff. }\end{array}$ & $\begin{array}{c}\text { std } \\
\text { error }\end{array}$ & $\begin{array}{c}\text { resulting effect } \\
\text { on mkt-share } \\
\text { (\% change })\end{array}$ & $\begin{array}{c}\text { implied value of } \\
\text { parameters } \\
\text { (absolute values) }\end{array}$ & $\begin{array}{c}\text { resulting effect } \\
\text { on iceberg costs } \\
\text { (\% change })\end{array}$ \\
\hline Intau $\left(^{*}\right)$ & $\mathbf{- 2 . 6 3 3}$ & 0.302 & $\mathbf{- 0 . 2 2 2}$ & $\theta=2.633$ & - \\
Indist $\left(^{*}\right)$ & $\mathbf{- 0 . 8 1 2}$ & 0.006 & $\mathbf{- 0 . 0 7 4}$ & $\rho=0.309$ & $\mathbf{0 . 0 3 0}$ \\
borders & $\mathbf{1 . 2 6 0}$ & 0.202 & $\mathbf{3 . 5 2 4}$ & $\xi_{1}=0.479$ & $\mathbf{0 . 6 1 4}$ \\
language & $\mathbf{0 . 9 0 7}$ & 0.175 & $\mathbf{2 . 4 7 7}$ & $\xi_{2}=0.345$ & $\mathbf{0 . 4 1 1}$ \\
colony & $\mathbf{0 . 7 5 1}$ & 0.228 & $\mathbf{2 . 1 1 8}$ & $\xi_{3}=0.285$ & $\mathbf{0 . 3 3 0}$ \\
legal & $\mathbf{0 . 3 2 0}$ & 0.106 & $\mathbf{1 . 3 7 7}$ & $\xi_{4}=0.122$ & $\mathbf{0 . 1 2 9}$ \\
\hline
\end{tabular}

(*) The resulting effects on market-shares and iceberg costs are computed assuming a $10 \%$ increase in the value of the listed explanatory variables.

It is worth mentioning that the result obtained in Table F.1 appears to be very close to the estimates of Buono and Lalanne (2012). In their paper, trade elasticity to tariffs is 
estimated by using a standard gravity model and performing different robustness checks. ${ }^{46}$ Since the coefficient on tariffs corresponds to the shape parameter of the EK efficiency distributions, their estimated trade elasticities turn out to be directly comparable with the various estimates of $\theta$ in literature. By running a Tobit "within" regression, Buono and Lalanne obtain a value of 2.87 , that becomes 2.74 when running a model in difference, estimated with $2 S L S{ }^{47}$

As the regression model outlined in this Appendix is just adapted, and not specifically derived for running this kind of estimation, the measure of 2.63 cannot be interpreted as a point estimation of the aggregate trade elasticity for the whole manufactures. Rather, it is a confirmation that aggregate trade elasticity is likely to be larger than what suggested by previous estimates. New evidence on this point comes from the work of Bekkers (2013), already mentioned in footnote 20 in Section 3.4.

\section{G Equations for the counterfactual simulation}

Equations (19)-(23) are basically built on a bulk of equations comprised of (1),(3), (4) and (6). In a simplified two-country economy, equation (3) reduces to $\Phi_{i, k}=T_{i, k} c_{i, k}^{-\theta_{k}}+\Phi_{i, k}^{-i}$, where $\Phi_{i, k}^{-i} \equiv T_{n, k} c_{n, k}^{-\theta_{k}} d_{i n, k}^{-\theta_{k}}$. As country $i$ is characterized as a small economy, shocks that take place in $i$ do not alter the value of state variables in country $n$, namely $T_{n, k}, p_{n, k}$ and $w_{n}$ (obviously, for each $k=1, \ldots, K)$. As iceberg costs are also unaffected, $\Phi_{i, k}^{-i}$ turns out to be the same after and before shocks in $T_{i, h}$. This means that $\Phi_{i, k}-T_{i, k} c_{i, k}^{-\theta_{k}}=\Phi_{i, k}^{-i}=\Phi_{i, k}^{\prime}-\left(T_{i, k}^{\prime} c_{i, k}^{\prime}\right)^{-\theta_{k}}$, where $\Phi_{i, k}^{\prime}=\left(p_{i, k} / \gamma_{k}\right)^{-1 / \theta_{k}}$ comes from (4) By using (1), it is straightforward to derive equation (21).

The starting point for retrieving equation (20), instead, is given by the inverse of equation( 6 ), re-written as follows:

$$
\frac{1}{\pi_{n i, k}}=\frac{\Phi_{n, k}}{T_{i, k} c_{i, k}^{-\theta_{k}} d_{n i, k}^{-\theta_{k}}}=1+\frac{T_{n, k} c_{n, k}^{-\theta_{k}}}{T_{i, k} c_{i, k}^{-\theta_{k}} d_{n i, k}^{-\theta_{k}}},
$$

as $\Phi_{n, k}=T_{i, k} c_{i, k}^{-\theta_{k}} d_{n i, k}^{-\theta_{k}}+T_{n, k} c_{n, k}^{-\theta_{k}}$. Very simple steps lead to:

$$
\frac{1-\pi_{n i, k}}{\pi_{n i, k}} T_{i, k} c_{i, k}^{-\theta_{k}}=T_{n, k} c_{n, k}^{-\theta_{k}} d_{n i, k}^{-\theta_{k}} .
$$

\footnotetext{
${ }^{46}$ Their paper aims at evaluating whether tariff barriers inhibit trade at the "extensive margin" (i.e. by lowering the entry of firms in the export market) or at the "intensive margin" (i.e. by reducing the volume of export for each producers). They control for endogeneity in tariff-changes over time and for zeros in trade-flows data. Their finding suggests that the number of firms exporting to a given destination is somehow related to the level of tariffs. Nevertheless, tariff reductions turn out to be associated with an increase in shipments by incumbent exporters, leaving the number of exporting firms virtually unchanged.

${ }^{47}$ Buono and Lalanne use sectoral data, as it has been done in this paper; consequently, for each country pair they have more observations at any moment in time. They impose the restriction on trade elasticities to be the same across industries. Then, they exploit the panel dimension of their dataset and run many "within regressions", characterized by the inclusion of a country-sector fixed effect.
} 
Notice that the right-hand side of the above equation does not vary after the technology shock in country $i$ and sector $h$. Thus, one can conclude that:

$$
\frac{1-\pi_{n i, k}^{\prime}}{\pi_{n i, k}^{\prime}} T_{i, k}^{\prime}\left(c_{i, k}^{\prime}\right)^{-\theta_{k}}=T_{n, k} c_{n, k}^{-\theta_{k}} d_{n i, k}^{-\theta_{k}} .
$$

By putting together the last two equations and using (6), it is quite comfortable to prove that (20) holds.

Equation (19), instead, is simply derived by plugging equation (6) into (4), and dividing the resulting expression for $p_{i, k}$ by its analogous for $p_{i, k}^{\prime}$.

It is a bit more cumbersome to derive equation (22). To accomplish this task, one has to assume trade balance between $i$ and $n$ at aggregate level. Thus, aggregate spending in country $i$, namely $X_{i}$, turns out to be equal to the aggregate national income, namely $Y_{i}$. Under this assumption, the market-clearing condition for each sector is: $w_{i} L_{i, k}=\pi_{i i, k} \alpha_{k} Y_{i}+\pi_{n i, k} \alpha_{k} Y_{n}$, where $Y_{i}=w_{i} L_{i}$ and $\alpha_{k} Y_{i}$ is the overall spending by consumers form $i$ in goods produced by sector $k^{48}$ Provided that, in the open economy, $L_{i, k}=s_{i, k} Y_{i}$, with a bit of algebra one can prove that:

$$
\frac{1-\pi_{i i, k} \alpha_{k} / s_{i, k}}{\pi_{n i, k} \alpha_{k} / s_{i, k} w_{i}}=\frac{L_{n}}{L_{i}} w_{n}
$$

Since countries' labor endowments are fixed and $w_{n}$ is not affected by changes in $T_{i, k}$, one can derive equation (22) by equalizing the left-hand side of this equation with its corresponding expression in the counterfactual scenario, where $\pi_{n i, k}$ and $\pi_{i i, k}$ are replaced by $\pi_{n i, k}^{\prime}$ and $\pi_{i i, k}^{\prime}$, and $s_{i, k}$ and $w_{i}$ by $s_{i, k}^{\prime}$ and $w_{i}^{\prime}$, respectively.

Finally, equation (23) simply states that sectoral shares in total manufacturing employment still sum up to one, after being re-defined by the reallocation process that follows form the change in trade patterns induced by the technology shock.

\footnotetext{
${ }^{48}$ Any sector $k$ absorbs a share $\alpha_{k}$ of the overall spending of a country, provided that utility is Cobb Douglas with coefficient $\alpha_{k}$ (which is a sort of teste parameter) associated to the amount consumed of the product category $k$.
} 


\section{References}

[1] Alvarez, F. and R. Lucas (2007): "General Equilibrium Analysis of the Eaton-Kortum Model of International Trade", Journal of Monetary Economics, Vol.54(6), pp. 1726-1768

[2] Anderson, J. and E. Van Wincoop (2003): "Gravity with Gravitas: A Solution to the Border Puzzle", American Economic Review, Vol.93, pp. 170-192

[3] Arkolakis, C., A. Costinot and A. Rodriguéz-Clare (2012): "New Trade Models, Same Old Gains?", American Economic Review, Vol. 102 (1), pp. 94-13

[4] Arkolakis, C., S. Demidova, P. Klenow and A. Rodríguez-Clare (2008): "Endogenous Variety and the Gains from Trade", American Economic Review, Vol. 98 (2), pp. 444450

[5] Armington, P. (1969): "A Theory of Demand for Products Distinguished by Place of Production", IMF Staff Papers, Vol.16 (1), pp. 159-78

[6] Balassa, B. (1965): "Trade Liberalization and Revealed Comparative Advantage", The Manchester School of Economic and Social Studies, Vol. 32, pp. 99-123

[7] Bekkers, E. (2013): "Estimating Trade Elasticities and Asymmetric Trade Costs under Firm Heterogeneity", mimeo, Johannes Kepler University - Linz

[8] Bernard, A., J. Eaton, B. Jensen and S. Kortum (2003): "Plants and Productivity in International Trade", American Economic Review, Vol.93 (4), pp. 1268-1290

[9] Bolatto, S., and M. Sbracia (2013): "Deconstructing the Gains from Trade: Selection of Industries vs. Reallocation of Workers", mimeo, University of Turin and Banca d'Italia

[10] Broda, C., and D. Weinstein (2006): "Globalization and the Gains from Variety", Quarterly Journal of Economics, Vol. 121 (2), pp. 541-585

[11] Buono, I. and G. Lalanne (2012): "The Effect of the Uruguay Round on the Intensive and Extensive Margins of Trade", Journal of International Economics, Vol. 86 (2), pp. 269-283

[12] Caliendo, L. and F. Parro (2012): "Estimates of the Trade and Welfare Effects of NAFTA", NBER Working Paper 18508, National Bureau of Economic Research

[13] Costinot, A., D. Donaldson and I. Komunjer (2012): "What Goods Do Countries Trade? A Quantitative Exploration of Ricardo's Ideas", Review of Economic Studies, Vol. 79 (2), pp. $581-608$

[14] Chen, N., and D. Novy (2012): "On the Measurement of Trade Costs: Direct vs. Indirect Approaches to Quantifying Standards and Technical Regulations", World Trade Review, Vol. 11 (03), pp. 401-414

[15] Chor, D. (2010): "Unpacking Sources of Comparative Advantage: A Quantitative Approach", Journal of International Economics, Vol.82 (2), pp. 152-167 
[16] Demidova, S., and A. Rodríguez-Clare (2009): "Trade Policy under Firm-Level Heterogeneity in a Small Economy", Journal of International Economics, Elsevier, Vol. 78(1), pp. $100-112$

[17] Di Giovanni, J., and A. Levchenko (2010): "Putting the Parts Together: Trade, Vertical Linkages, and Business Cycle Comovement", American Economic Journal: Macroeconomics, Vol. 2 (2), pp. 95-124

[18] Dixit, A. and J. Stiglitz (1977): "Monopolistic Competition and Optimum Product Diversity", American Economic Review, Vol.67 (3), pp. 297-309

[19] Eaton, J., and S. Kortum (1999): "International Technology Diffusion: Theory and Measurement", International Economic Review, Vol.40 (3), pp. 537-70

[20] Eaton, J., and S. Kortum (2002): "Technology, Geography and Trade", Econometrica, Vol.70 (5), pp. 1741-1779

[21] Eaton, J., S. Kortum, B. Neiman, and J. Romalis (2011): "Trade and the Global Recession", NBER Working Papers 16666, National Bureau of Economic Research

[22] Feenstra, R., (1994): "New Product Varieties and the Measurement of International Prices", American Economic Review, Vol. 84 (1), pp. 157-177

[23] Finicelli, A., P. Pagano and M. Sbracia (2013): "Ricardian Selection", Journal of International Economics, Vol. 89 (1), pp. 96-109

[24] Finicelli, A., P. Pagano and M. Sbracia (2009): "Trade-revealed TFP", Bank of Italy Temi di Discussione (Working Paper), N. 729

[25] Hummels, D. and A. Skiba (2004): "Shipping the Good Apples Out? An Empirical Confirmation of the Alchian-Allen Conjecture", Journal of Political Economy, Vol.112 (6), pp. 1384-1402

[26] Head, K. and T. Mayer (2002): "Illusory Border Effects: Distance Mismeasurement Inflates Estimates of Home Bias in Trade", CEPII Working Paper 2002-01

[27] Imbs, J., and I. Mejean (2009): "Elasticity Optimism", CEPR Discussion Papers 717n, C.E.P.R. Discussion Papers

[28] Krugman, P. (1980): "Scale Economies, Product Differentiation and the Pattern of Trade", American Economic Review, Vol. 70 (5), pp. 950-959

[29] Krugman, P. (1981): "Intra-industry Specialization and the Gains from Trade", Journal of Political Economy, Vol. 89 (5), pp. 959-973

[30] Levchenko, A. and J. Zhang (2011): "The Evolution of Comparative Advantage: Measurement and Welfare Implications", NBER Working Paper 16806, National Bureau of Economic Research

[31] Levchenko, A. and J. Zhang (2013): "Ricardian Productivity Differences and the Gains from Trade", NBER Working Paper 19641, National Bureau of Economic Research 
[32] Mayer, T. and S. Zignago (2005): "Market Access in Global and Regional Trade", CEPII Working Paper 2005-02

[33] Melitz, M. (2003): "The Impact of Trade on Intra-Industry Reallocations and Aggregate Industry Productivity", Econometrica, Vol. 71 (6), pp. 1695-1725

[34] Nicita, A. and M. Olarreaga (2006): "Trade, Production and Protection 1976-2004: Technical Note", mimeo, Development Economics Research Group (Trade) - World Bank

[35] Pavcnik, N. (2002): "Trade Liberalization, Exit, and Productivity Improvements: Evidence from Chilean Plants", Review of Economic Studies, Vol. 69 (1), pp. 245-276.

[36] Samuelson, P. (1952): "The Transfer Problem and Transport Costs: the Terms of Trade when Impediments are Absent", The Economic Journal, Vol.62 (246), pp.278-304

[37] Santos Silva, J. and S. Tenreyro (2006): "The Log of Gravity", The Review of Economics and Statistics, Vol.88 (4), pp. 641-658

[38] Shikher, S. (2005): "Accounting for International Trade", mimeo, Suffolk University

[39] Shikher, S. (2011): "Capital, Technology, and Specialization in the Neoclassical Model", Journal of International Economics, Vol. 83 (2), pp. 229-242

[40] Shikher, S. (2012): "Putting Industries into the Eaton-Kortum Model", Journal of International Trade and Economic Development, Vol. 21 (6), pp. 807-837

[41] Simonovska, I. and M. Waugh (2011): "The Elasticity of Trade: Estimates and Evidence", NBER Working Papers 16796, National Bureau of Economic Research

[42] Waugh, M. (2010): "International Trade and Income Differences", American Economic Review, Vol.100 (5), pp. 2093-2124

\section{Databases}

[43] CEPII (2011): "The CEPII GeoDist database" and "The CEPII Trade, Production and Bilateral Protection Database", CEPII - Centre d'Etudes Prospectives et d'Informations Internationales

[44] OECD (2010): "STAN Bilateral Trade Database 2008" and "STAN Industry 2008", STAN: OECD Structural Analysis Statistics

[45] OECD (2011): "STAN Input-output: Total tables", STAN: OECD Structural Analysis Statistics

[46] U.S. Bureau of Labor Statistics (2010): "International Comparisons of Hourly Compensation Costs in Manufacturing", International Labor Comparisons (ILC) program 